\title{
MOVI: Projeto de móvel multifuncional para a casa do estudante universitário da UFPel
}

\author{
MOVI: Multifunctional furniture \\ project for the University \\ Student House at UFPel
}

\author{
Janisse Roberta Lüdtke ${ }^{[1]}$, Liege Dias Lannes Soares ${ }^{[2]}$
}

\begin{abstract}
Resumo: Este artigo apresenta um resumo do trabalho de conclusão de curso, o qual aborda como objetivo a criação de um móvel multifuncional que otimiza o espaço habitado e contribui para as práticas de estudos dos residentes da Casa do Estudante Universitário (CEU) da Universidade Federal de Pelotas (UFPel). Para isto, utilizou-se uma pesquisa bibliográfica para embasar e aplicar conceitos de Design, empregando ferramentas metodológicas baseadas em Löbach (2001) e Bonsiepe (1984). Este artigo tem foco principal no desenvolvimento do projeto, no qual foram elaborados análises, desenhos, modelos 3D, estudos de estrutura, encaixes. O projeto foi aplicado na planta da CEU a partir de um software 3D, apresentando boa relação entre ambiente x usuário e possibilidade de ser confeccionado em escala real.

Palavras-chave: Design de Mobiliário. Espaços Reduzidos. Multifuncionalidade.

Abstract: This article presents a summary of the course completion work, which aims to create a multifunctional piece of furniture that optimizes the living space and contributes to the study practices of residents of the University Student House (CEU) of the Federal University of Pelotas (UFPel). For this, a bibliographic research was used to support and apply Design concepts, using methodological tools based on Löbach (2001) and Bonsiepe (1984). This article is mainly focused on the development of the project, in which analyses, drawings, 3D models, structure studies, fittings were elaborated. The project was applied at the CEU plant using 3D software, showing a good relationship between environment $x$ user and the possibility of being made in full scale.
\end{abstract}

Keywords: Furniture Design. Reduced Spaces. Multifunctionality.

[1] Bacharela em Design, IFSUL. janisserl@hotmail.com

[2] Mestre em Arquitetura e Urbanismo, UFPEL. liegelannes@ifsul.edu.br 


\section{INTRODUÇÃO}

Através do processo de expansão das Universidades Federais, é crescente a necessidade de vagas em moradias estudantis, com isso, torna-se necessária a avaliação dos espaços que estão sendo oferecidos aos universitários. Essas moradias acolhem e dão suporte para estudantes oriundos de outras cidades, destinadas para abrigo, ao convívio social e local para exercer suas atividades acadêmicas extraclasses (GOETTEMS, 2012).

A prática do estudo exige um espaço, minimamente apropriado para que a quem está o fazendo, tenha apenas preocupações relacionadas a adquirir e construir conhecimentos. No entanto, o estudante tem se deparado com espaços reduzidos que acabam por dificultar seu processo de aprendizagem.

Folz (2003) e Pezzini e Ely (2010) explicam que, a redução da área útil das habitações é um fator em crescimento ano após ano e essa causa tem se manifestado principalmente em apartamentos em centros urbanos. Sendo assim, devem ser (re)pensados uma melhor usabilidade dos produtos, impactando positivamente no cotidiano dos usuários e consequentemente no seu desempenho pessoal. Portanto, se faz necessário pensar em estratégias que possam contribuir ao desempenho dos discentes da universidade.

Deste modo, a presente pesquisa tem como objetivo geral criar um móvel multifuncional, sendo ora mesa e ora cadeira, que otimize o espaço habitado e contribua para as práticas de estudos dos universitários residentes da Casa do Estudante Universitário da UFPel (CEU).

A CEU, é um Programa de Moradia Estudantil (PME) da Universidade Federal de Pelotas (UFPel), tem como objetivo alojar acadêmicos oriundos de outras cidades e que tenham comprovada situação de vulnerabilidade.

Atualmente, o PME disponibiliza um imóvel para moradia estudantil denominado Casa do Estudante Universitário (CEU), e está localizado na rua três de maio, 1212, centro de Pelotas RS, situada no quarteirão compreendido entre as ruas Barão de santa Tecla, Dom Pedro II, Três de Maio e Manduca Rodrigues. 
A CEU possui capacidade para acolher até 300 moradores, entre 60 apartamentos, dos quais 40 são de 2 quartos para até 6 pessoas, e o restante de 1 quarto, para até 3 pessoas. Esses apartamentos são mobiliados com utensílios básicos, incluindo guarda-roupas, camas, beliches, poltronas, mesas, cadeiras, geladeira, fogão elétrico e ducha eletrônica, conforme informado no site da UFPel/PRAE.

A figura 1 a seguir, mostra os três tipos de plantas existentes na CEU, visto que a ideia do projeto de móvel é de considerar tanto os apartamentos de 1, quanto os de 2 dormitórios. A sala foi o ambiente escolhido para a aplicação do estudo, pois é o local de convívio social, por ter a área mais ampla e livre de móveis já fornecidos pela instituição. A possibilidade de uso do móvel no quarto foi descartada, pois acredita-se que não haja espaço livre, pelo fato do ambiente ter que acomodar três camas e guarda-roupas.

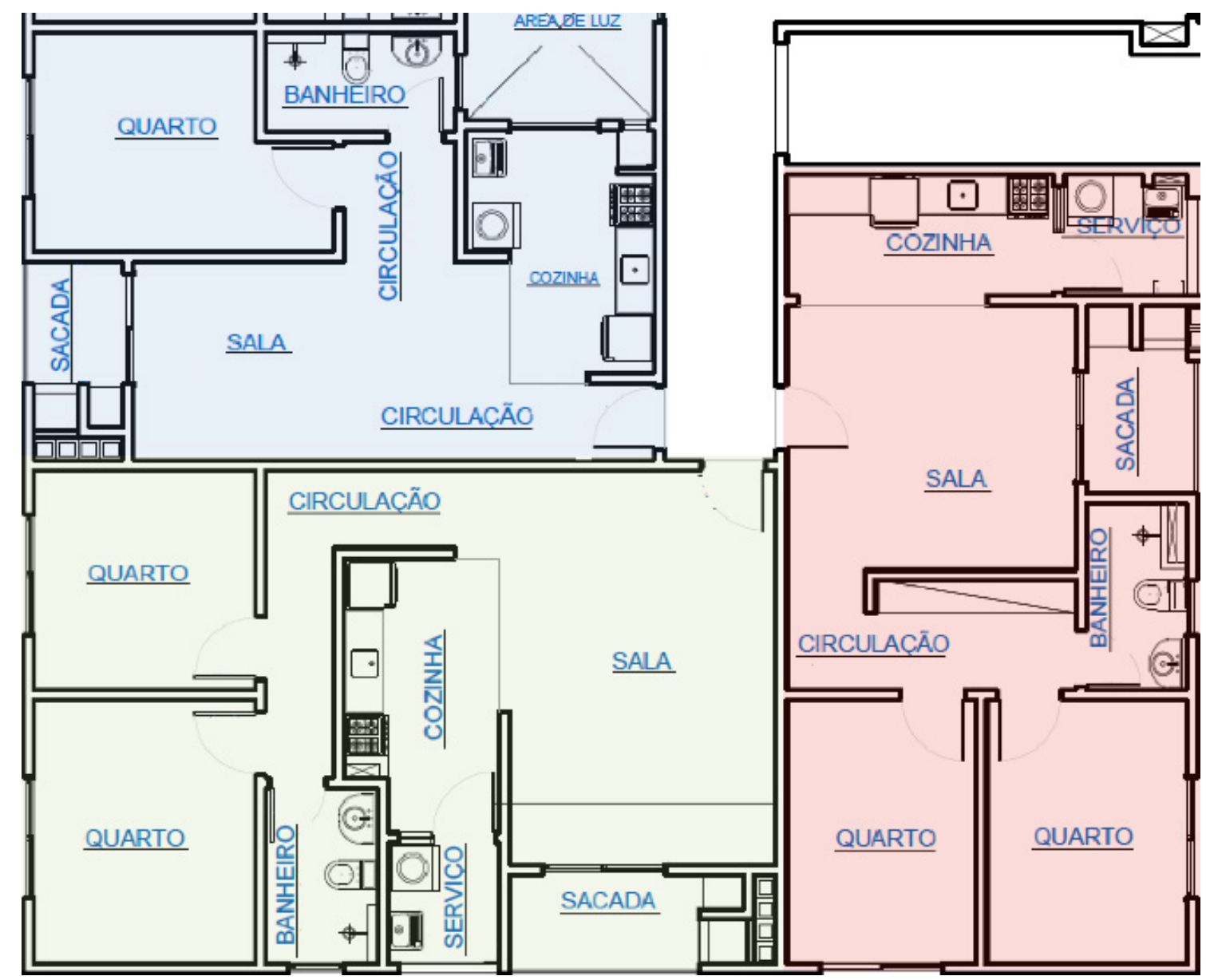

Figura 1 - Modelos de planta baixa da CEU. Fonte: UFPel, 2019. 
O projeto de mobiliário tende a contribuir com a realização das atividades de estudo de forma adequada e convidativa para os usuários, tendo em vista, a preocupação de atender às necessidades ergonômicas dos estudantes e ao ambiente reduzido.

\section{DESIGN E ESPAÇO}

Löbach (2001) e Ching (2013), argumentam que o projeto de espaço é o planejamento, o layout interno das edificações, onde esses ambientes são adaptados às necessidades físicas e psíquicas dos seres humanos para satisfazer suas vontades básicas, como abrigo e proteção. Nesses ambientes, são estabelecidas a maior parte de nossas atividades, tanto domésticas quanto de estudos e trabalho. Um ambiente que atende essas necessidades pode influenciar o humor, a personalidade e até mesmo o bem-estar de cada morador.

Para a acomodação de 3 ou 6 moradores em um apartamento, é necessário um projeto de espaço adequado, para que os estudantes tenham a capacidade de desenvolver seus estudos e trabalhos, de forma que não prejudique ou atrapalhe seu colega de moradia, facilitando, a usabilidade e a interatividade entre humano e espaço.

Corrêa (2013), fala que a diminuição nos espaços dos ambientes vai de encontro com o aumento das atividades realizadas em seus interiores, portanto, o projeto de mobiliário para essas áreas deve se preocupar em solucionar todas essas questões com propostas criativas que atendam às necessidades dos envolvidos.

Deve-se levar em consideração, no momento de criação do mobiliário, a importância das zonas de distanciamento entre o ser humano e o mobiliário como relata Ching (2013). Um exemplo disso é o ato de sentar-se adequadamente e conseguir alcançar um objeto sobre a mesa à frente, ou ainda, o espaço necessário para os pés do usuário entre uma poltrona e outra.

A partir desse estudo proposto por Ching (2013) é possível ter um ponto de partida no momento de projetar um móvel em um ambiente que já possui móveis, como no caso da CEU. 
Essa análise de dimensões diminui a possibilidade do que Pezzini e Ely (2010) chamam de impacto negativo na qualidade de vida do indivíduo, pois com esse estudo será possível distribuir o móvel de maneira confortável no apartamento da CEU.

Segundo Ching (2013) e Toledo (2017), além do estudo do espaço físico do ambiente, existe o que chamamos de Espaço Pessoal, que é a percepção dos usos apropriados do espaço em torno de seus corpos, e esse espaço varia conforme a cultura, as questões sociais e/ou religiosas de cada indivíduo. Esses espaços se classificam em quatro zonas, conforme apontado abaixo:

- Intimate Space (Zona intima): permite o contato físico; a invasão por um estranho pode resultar em desconforto.

- Personal Space (Zona pessoal): permite aos amigos se aproximar e possivelmente ingressar brevemente nos limites mais íntimos, é possível conversar com níveis de voz baixos.

- Social Space (Zona social): apropriada para negociações informais, sociais e profissionais; a comunicação ocorre sob níveis de voz normais e aumentados.

- Public Space (Zona pública): aceitável para relacionamentos de comportamento formal ou hierárquico; são necessários níveis de voz mais altos com enunciados mais claros.

A distância física entre pessoas é um conceito variável no tempo e no espaço, sendo socialmente construída e interligada à cultura e aos hábitos de diversos povos (TOLEDO, 2017. p. 9). É preciso abrir mão de algumas comodidades quando o objetivo é compartilhar espaços, tanto em moradia quando no local de trabalho. Quando se ocupa um espaço reduzido, com a presença de outras pessoas, são necessárias regras mínimas de convivência e bom senso, para evitar futuras divergências. 
Quando há o compartilhamento de um espaço reduzido com outras pessoas, como o caso da CEU, essa demarcação de limites pode ocorrer sobre algum mobiliário, utilizando a cama, um sofá, ou uma cadeira como limite de área intima.

\section{DESIGN DE MOBILIÁRIO}

Conforme Bello e Bello (2010), o design de mobiliário é a área especializada em estudar as funções, porém, é também a área responsável em agregar conceitos estéticos e cênicos ao móvel ou conjunto mobiliário, tornando-os muito mais do que somente utensílios, mas sim parte integrante e essencial do cotidiano humano em todos os seus aspectos.

Löbach (2001) explica que são 3 categorias que caracterizam as funções básicas do produto. A função Prática, tem relação direta com o uso, com ênfase na ergonomia, na facilidade do uso e na segurança. A função Estética, é bem como o nome já diz, tem relação direta com a beleza e bem-estar que o produto proporciona. E a função Simbólica é quando o objeto transmite um sinal ou signo, que com isso o usuário consegue fazer associações referenciais.

Essa abordagem das três funções, tem a finalidade de propor uma intenção para cada produto, para que assim, seja justificado a adequação ideal do objeto em cada determinado ambiente. Um mesmo móvel pode ter mais de uma função, mas apenas uma será dominante.

Dentro desse contexto de funções, há produtos que podem ser multifuncionais, ou seja, que executam mais de uma função prática, como por exemplo, um banco que também tem compartimento para guardar volumes. Móveis multifuncionais geralmente são aplicados aos ambientes reduzidos, onde Ching (2013) fala que tais uniões das funções num único móvel, utilizam o espaço de forma eficiente e deixam uma quantidade máxima de áreas de piso em torno deles.

Para projetar móveis em espaços reduzidos, é preciso ter o conhecimento das dimensões mínimas. Para tanto, o estudo da ergonomia é muito importante para o desenvol- 
vimento de um mobiliário, pois leva em consideração a relação humano/objeto, no sentido anatômico, visando o melhor conforto, eficácia e segurança do projeto proposto.

\section{ERGONOMIA}

A ergonomia, conforme lida (2005), está associada a todas as atividades produtivas humanas, tanto as de setor de serviços, até mesmo as de trabalho doméstico, atendendo de forma global, aspectos físicos, cognitivos, sociais, organizacionais, ambientais e outros. O objetivo da ergonomia é procurar reduzir as consequências nocivas nos usuários dos produtos, reduzindo fadiga, estresse, acidente, dores físicas, e garantindo saúde e segurança.

Para a aplicação da ergonomia nos produtos, se faz necessário o estudo do corpo humano em relação ao espaço. Esse estudo, se denomina como antropometria, que ajuda o designer a compreender as medidas e os movimentos do corpo humano, para projetar espaços/móveis que permitam o uso cômodo e adequado do usuário, explica Gibbs (2010).

$\mathrm{Na}$ imagem a seguir estão dimensionadas as 15 medidas corporais de adultos, das quais são base para projetar um produto de uso humano.
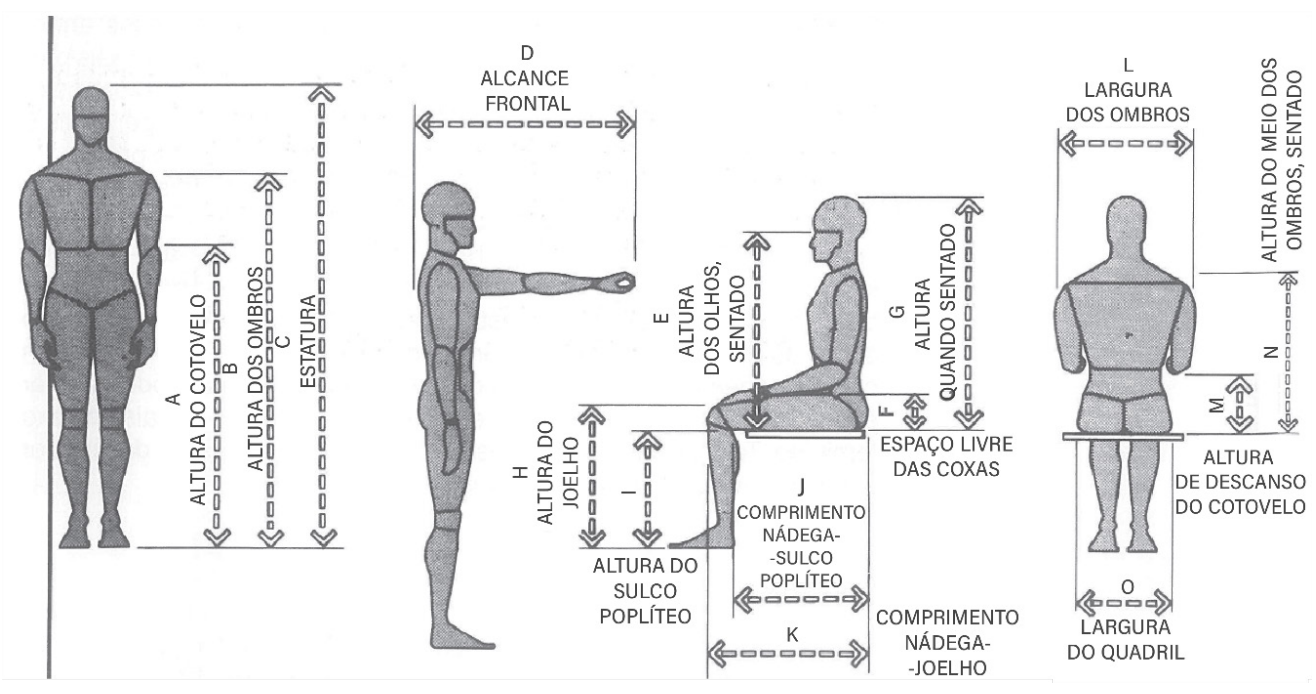

Figura 2 - Dimensões corporais dos adultos. Fonte: Panero; Zelnik (2008) p.102. 
Na figura 3, está a tabela de medidas referentes as dimensões apresentadas na figura 2, onde está representada pelos percentis 95 e 5 . O percentil $5 \%$ significa que $5 \%$ da população está abaixo daquele valor. O percentil 95\% significa que esse valor engloba $95 \%$ da população. Por exemplo, para projetar um armário aéreo, é necessário levar em consideração o percentil $5 \%$ para que as pessoas mais baixas possam alcançar, e para projetar uma porta de passagem, é preciso considerar o percentil 95\%, para que até mesmo as pessoas mais altas possam utilizar a passagem e não batam com a cabeça.

\begin{tabular}{|c|c|c|c|c|c|c|c|c|}
\hline \multicolumn{9}{|c|}{$\begin{array}{l}\text { Dimensões corporais de adultos, sexo masculino e feminino, } \\
\text { por sexo e percentis selecionados }\end{array}$} \\
\hline & $\mathrm{kg}$ & $\mathrm{cm}$ & $\mathrm{cm}$ & $\mathrm{cm}$ & $\mathrm{cm}$ & $\mathrm{cm}$ & $\mathrm{cm}$ & $\mathrm{cm}$ \\
\hline HOMENS & 97,7 & 120,9 & 155,7 & 188,6 & 87,4 & 86,5 & 19,1 & 99,0 \\
\hline ) MULHERES & 74,9 & $108,7^{*}$ & 141,4 & 172,8 & 80,6 & 79,6 & 14,9 & 91,5 \\
\hline HOMENS & 65,2 & 105,5 & 136,5 & 168,2 & 74,3 & 76,4 & 14,5 & 88,5 \\
\hline MULHERES & 47,4 & 96,5 & 122,9 & 152,3 & 67,7 & 69,5 & 10,4 & 81,2 \\
\hline & $\mathrm{H}$ & 1 & $\mathrm{~J}$ & $\mathrm{~K}$ & $L$ & $M$ & $\mathrm{~N}$ & 0 \\
\hline & $\mathrm{cm}$ & $\mathrm{cm}$ & $\mathrm{cm}$ & $\mathrm{cm}$ & $\mathrm{cm}$ & $\mathrm{cm}$ & $\mathrm{cm}$ & $\mathrm{cm}$ \\
\hline HOMENS & 60,3 & 47,8 & 55,1 & 65,4 & 52,9 & 29,7 & 69,6 & 42,2 \\
\hline ) MULHERES & $54,3^{*}$ & 44,2 & 52,7 & 62,0 & 46,8 & 27,1 & 63,1 & 41,6 \\
\hline HOMENS & 52,1 & 40,4 & 46,4 & 56,4 & 44,4 & 21,0 & 60,6 & 34,4 \\
\hline MULHERES & 46,7 & 37,8 & 43,7 & 53,3 & 38,6 & 19,2 & 54,2 & 35,4 \\
\hline
\end{tabular}

Figura 3 - Tabela das dimensões corporais de adultos (cm). Fonte: Panero; Zelnik (2008) p.102.

Panero e Zelnik (2008), disponibilizam alguns modelos de referência para aplicação em projetos, com uma abordagem voltada a antropometria. A imagem 4 a seguir, mostra as principais medidas da cadeira de trabalho a serem analisadas no momento do projeto do produto. 


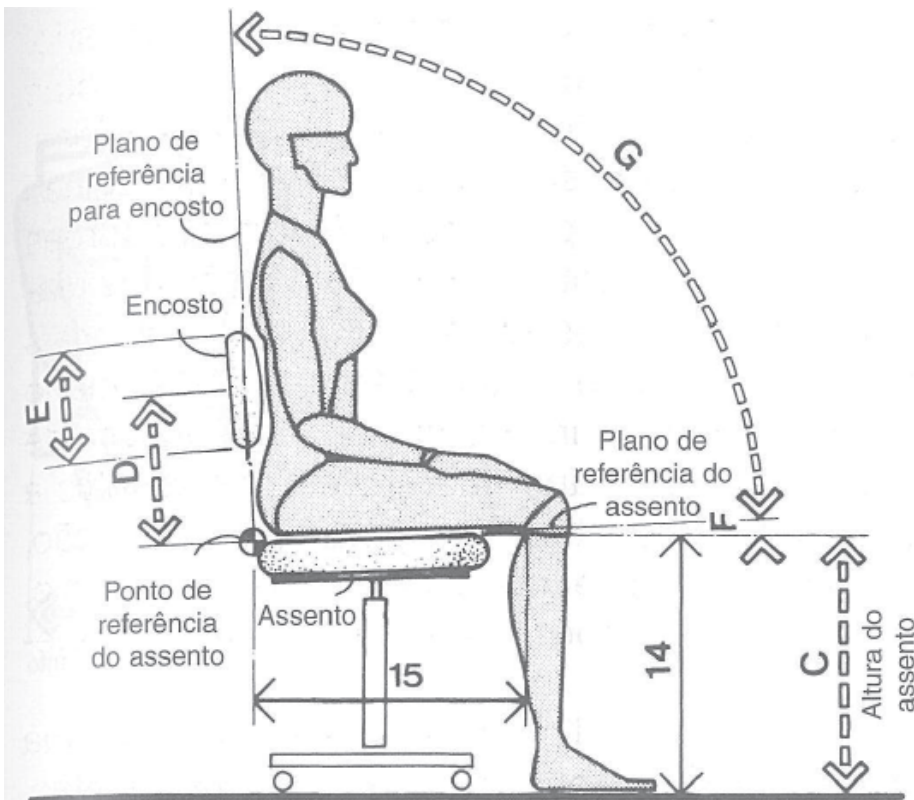

VISTA LATERAL

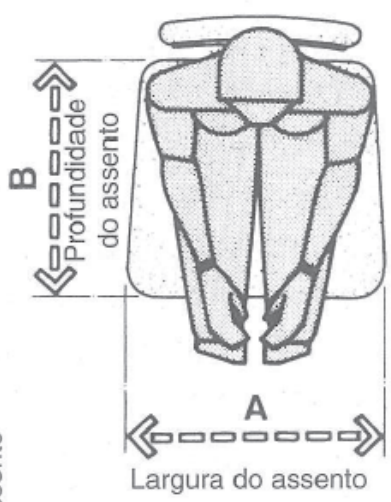

VISTA EM

PLANTA

MEDIDAS PRINCIPAIS DA CADEIRA DE TRABALHO

em centímetros $(\mathrm{cm})$

\begin{tabular}{|c|c|c|c|c|c|c|c|}
\hline & A & B & C & D & E & $F$ & G \\
\hline FONTE & $\begin{array}{l}\text { LARGURA } \\
\text { DO } \\
\text { ASSENTO }\end{array}$ & $\begin{array}{l}\text { PROFUNDI- } \\
\text { DADE DO } \\
\text { ASSENTO }\end{array}$ & $\begin{array}{l}\text { ALTURA } \\
\text { DO } \\
\text { ASSENTO }\end{array}$ & $\begin{array}{c}\text { ALTURA } \\
\text { DA LINHA } \\
\text { CENTRAL DO } \\
\text { ENCOSTO ATE } \\
\text { A SUPERFICIE } \\
\text { DO ASSENTO }\end{array}$ & $\begin{array}{l}\text { ALTURA } \\
\text { DO } \\
\text { ENCOSTO }\end{array}$ & $\begin{array}{c}\text { ÂNGULO DE } \\
\text { INCLINAÇÃO } \\
\text { DA } \\
\text { SUPERFICIE } \\
\text { DO ASSENTO }\end{array}$ & $\begin{array}{l}\text { ÂNGULO DO } \\
\text { ENCOSTO }\end{array}$ \\
\hline & $\mathrm{cm}$ & $\mathrm{cm}$ & $\mathrm{cm}$ & $\mathrm{cm}$ & $\mathrm{cm}$ & graus & graus \\
\hline $\begin{array}{l}5 \text { PANERO- } \\
\text { ZELNIK }\end{array}$ & $43,2-48,3$ & $39,4-40,6$ & $35,6-50,8$ & $19,2-25,4$ & $15,2-22,9$ & $0^{0}-5^{\circ}$ & $95^{\circ}-105^{\circ}$ \\
\hline
\end{tabular}

Figura 4-Medidas principais da cadeira de trabalho $(\mathrm{cm})$ Fonte: Panero; Zelnik (2008) e alterações do autor.

Deve-se atentar principalmente, na altura e na profundidade do assento, respectivamente denominados de " $\mathrm{B}$ " $\mathrm{e}$ " $\mathrm{C}$ "; no suporte para a região lombar preferencialmente com angulação "G" e a largura do assento "A".

Na figura 5 a seguir, podemos observar uma série de estudos antropométricos para planejamento e projeto de escritórios, onde Panero e Zelnik (2008) falam que a zona de trabalho deve ser suficiente para adequar todo tipo de equipamento, que o usuário necessita para executar seus serviços. 


\begin{tabular}{|c|c|}
\hline & $\mathrm{cm}$ \\
\hline A & $228,6-320,0$ \\
\hline$B$ & $76,2-91,4$ \\
\hline $\mathrm{C}$ & $76,2-121,9$ \\
\hline D & $15,2-30,5$ \\
\hline E & $152,4-182,9$ \\
\hline $\mathbf{F}$ & $76,2-106,7$ \\
\hline $\mathbf{G}$ & $35,6-45,7$ \\
\hline $\mathrm{H}$ & $40,6-50,8$ \\
\hline I & $45,7-55,9$ \\
\hline $\mathbf{J}$ & $45,7-61,0$ \\
\hline $\mathbf{K}$ & $15,2-61,0$ \\
\hline $\mathrm{L}$ & $152,4-213,4$ \\
\hline M & $61,0-76,2$ \\
\hline $\mathbf{N}$ & $73,7-76,2$ \\
\hline 0 & $38,1-45,7$ \\
\hline
\end{tabular}

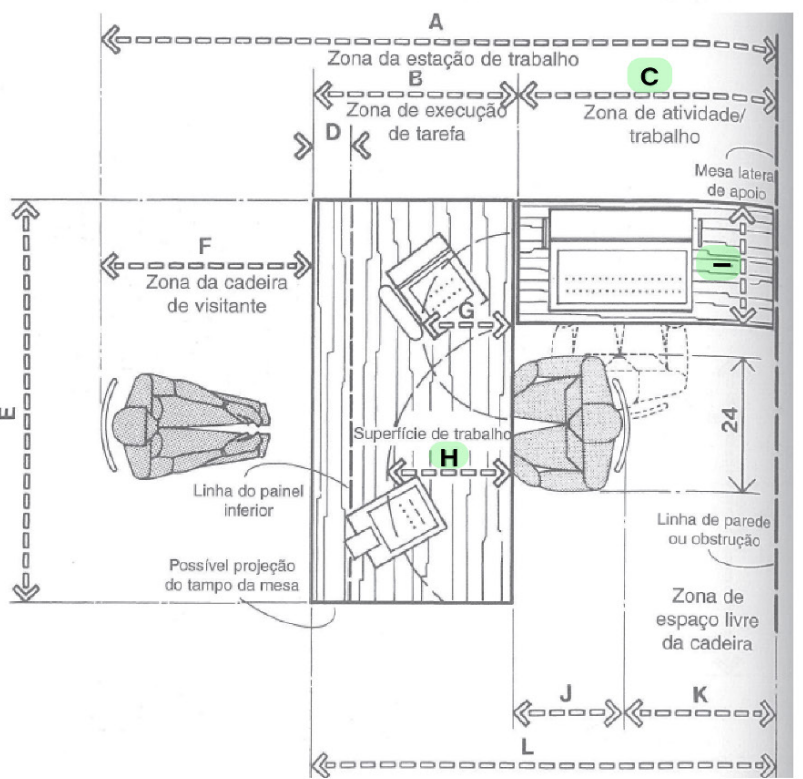

Ressaltando algumas medidas importantes para o projeto do móvel, na figura 5 , vemos que a medida " $\mathrm{H}$ " equivale a superfície real de trabalho, onde o usuário manuseia as atividades de mais frequência. Essa medida " $\mathrm{H}$ " tem valores próximos ao que se retrata na medida "I" largura da mesa lateral de apoio, com isso, entendemos que " $\mathrm{H}$ " e "I" são as medidas mínimas de largura que uma mesa de trabalho possa atingir (figura 5).

A medida " $C$ " representa a zona de atividade, onde deve ter o suficiente para acomodar uma cadeira, que também é o comprimento da mesa lateral de apoio. Também temos, o comprimento do raio da superfície de trabalho " $\mathrm{H}$ " da mesa principal " $\mathrm{E}$ ". Entendemos aqui, que " $C$ " é o comprimento médio entre o máximo e mínimo sugerido de uma estação de trabalho (figura 5).

A imagem a seguir, ilustra três medidas propostas por $\mathrm{Pa}$ nero e Zelnik (2008), relacionadas ao conjunto mesa e cadeira.

Na figura 6, a medida " $A$ " representa o total da altura da mesa, a letra " $B$ " retrata a medida mínima de $19,1 \mathrm{~cm}$ para o vão das coxas, e "C" é a altura da mesa em relação ao assento. O percentil 95 é o indicado nas medidas de " $\mathrm{B}$ " e " $\mathrm{C}$ " pois o maior espaço para as pernas pode ser usado tanto por pessoas pequenas quanto para pessoas grandes. Caso contrário, se for aplicado um percentil menor, não ficaria confortável para as pessoas de maior estatura. 

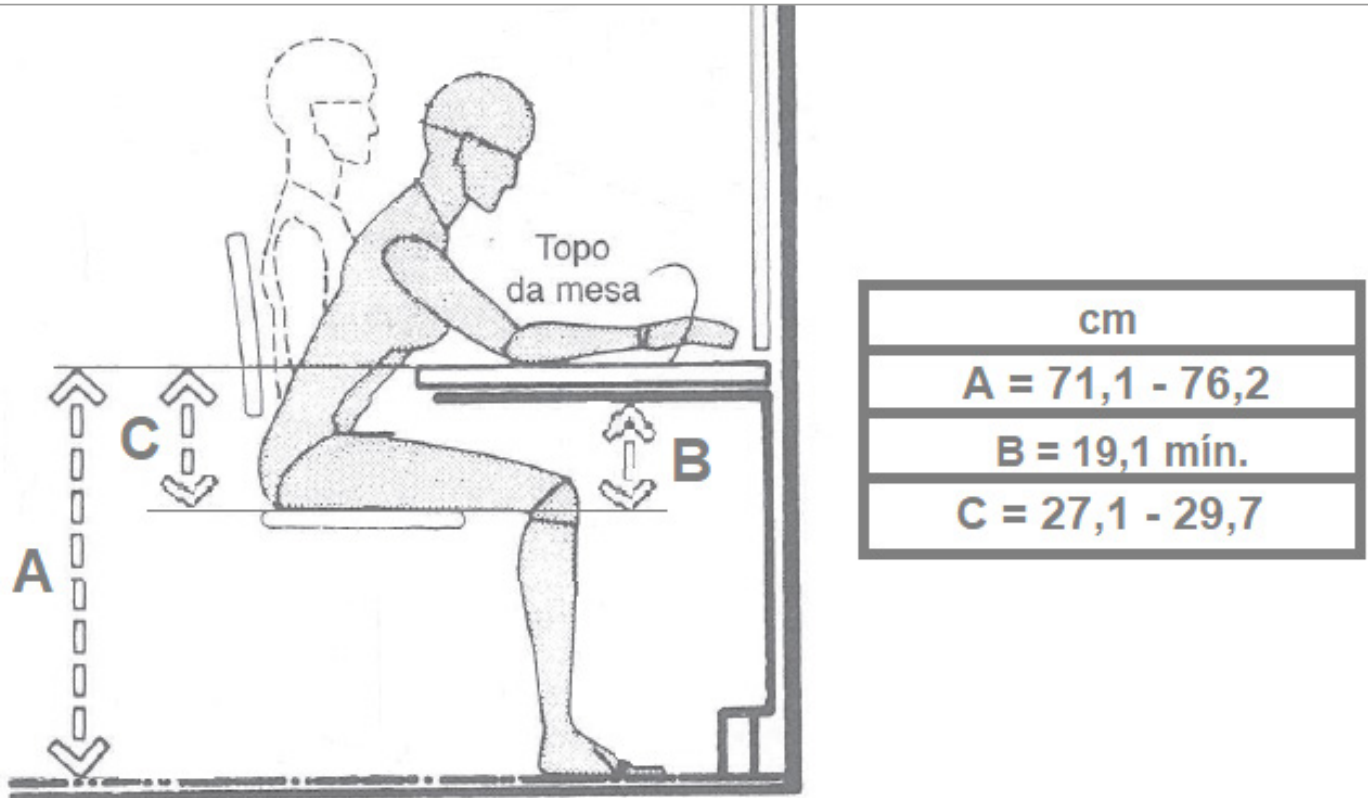

ESCRIVANINHA OU PENTEADEIRA
Figura 6 - Escrivaninha: Relação entre a altura da mesa e o assento $(\mathrm{cm})$. Fonte: Panero e Zelnik (2008) p. 153

Essas medidas de referência disponibilizadas por Panero e Zelnik (2008), são muito relevantes, pois auxiliam os designers e facilita o método de compreensão no momento de desenvolver um projeto.

\section{METODOLOGIA}

Inicialmente para este projeto, seria levado em consideração a experiência dos estudantes moradores da CEU, como usuários do local, porém, devido a pandemia da nova Covid-19, que se estendeu ao longo dos anos 2020 e 2021, não foi viável este contato, por via das recomendações de segurança da OMS (Organização Mundial de Saúde).

A pandemia foi se estendendo, e por conta do cancelamento das aulas presenciais e o retorno previsto remotamente, os estudantes residentes da CEU, foram voltando para suas cidades natais. Devido a essa situação, não foi possível promover as visitações e as entrevistas no local com os estudantes.

Contudo, para solução deste impasse, as necessidades dos usuários serão justificadas através de autores como, Ching, Löbach, Panero e Zelnik, lida e entre outros, que fundamentam e indicam a base do projeto. 
O trabalho, aqui apresentado, é caracterizado como qualitativo e tem o propósito exploratório, em que a partir de um estudo de caso, busca utilizar uma revisão bibliográfica para compreender, embasar e aplicar/projetar soluções para o problema em questão.

Portanto, para suprir essa demanda, será aplicado a metodologia de processo de design de Löbach (2001), que sugere a metodologia com divisão em 4 fases de ações. Contudo, ainda será acrescentado uma outra fase, a técnica analítica de Gui Bonsiepe (1984), que esclarece o entendimento do problema com base nos produtos similares encontrados no mercado. Podemos observar imagem a baixo, a proposta de metodologia composta pela união de Bonsiepe (1984) e Löbach (2001).

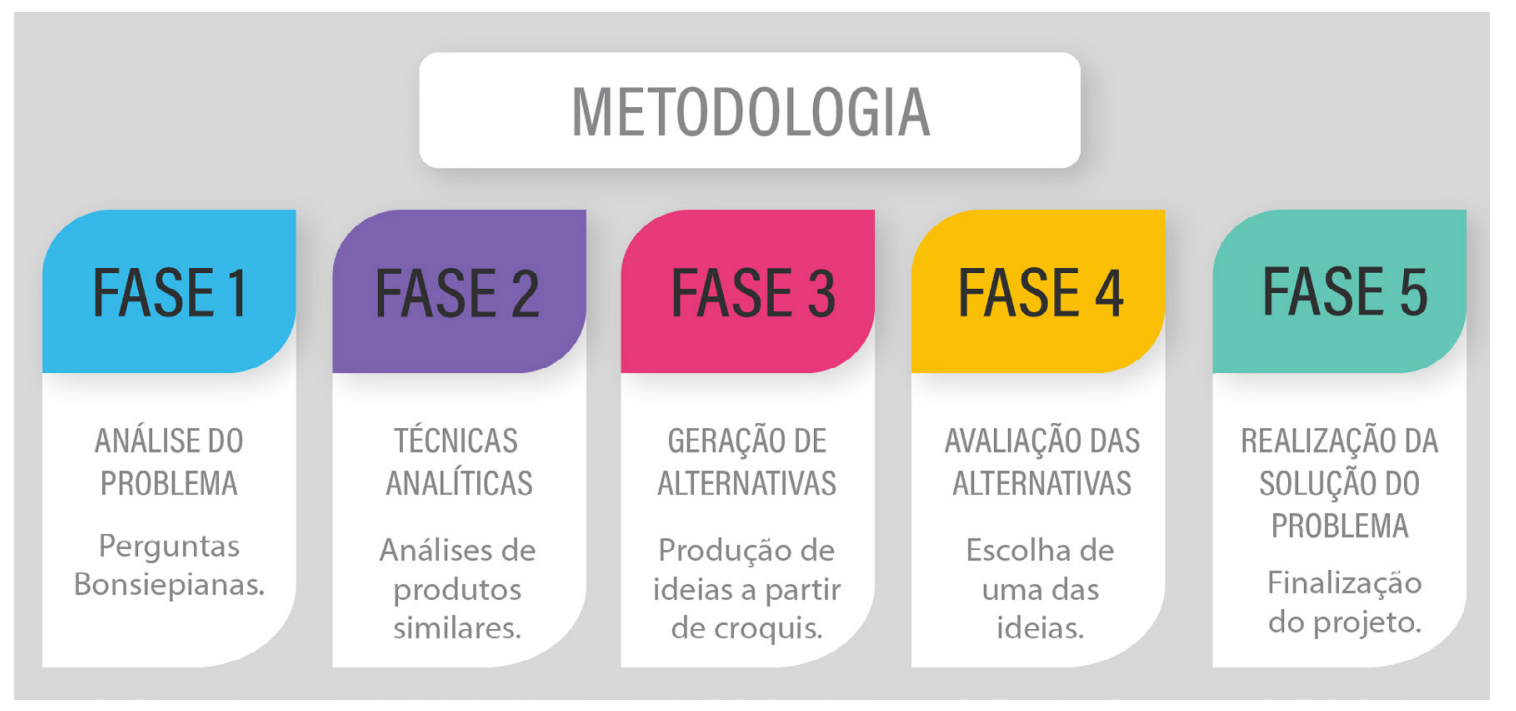

Na fase de análise de problema, serão aplicadas as perguntas bonsipianas, propostas por Bonsiepe (1984), de forma que esses questionamentos tornem possível analisar e esclarecer o problema de pesquisa. As técnicas analíticas da fase 2, Bonsiepe (1984), retrata as análises como estruturas para entender os produtos similares encontrados no mercado.
Figura 7 - Metodologia de projeto. Fonte: Desenvolvido pela autora com base em Löbach (2001) e Bonsiepe (1984). 
Na fase de geração de alternativas, que de acordo com Löbach (2001), será o momento de pós análise e começo de ação, iniciando a produção de ideias com base nas técnicas analíticas realizadas. Na avaliação das alternativas, Löbach (2001) diz que é preciso visualizar todas as alternativas geradas para que seja escolhida a ideia mais plausível que solucionará o problema, auxiliando o modo em que os estudantes desenvolvem suas atividades e conseguir englobar as diversas outras atividades exercidas neste mesmo local.

Na realização da solução do problema, Löbach (2001) ressalta que é preciso uma materialização da alternativa escolhida, para revisar e aperfeiçoar detalhes que inicialmente passam despercebidos, onde a partir deste protótipo, será possível determinar as características de estrutura, dimensões, material e acabamentos.

Logo, este protótipo será apresentado através de software de projetos em 3D e em maquete em escala, simulando a forma do móvel, a estrutura, diferentes formas de uso, multifuncionalidade, materiais, acabamentos e detalhes. A partir dessas 5 fases serão gerados os requisitos projetuais que apontarão os caminhos para encontrar as melhores escolhas para o desenvolvimento do projeto de design de mobiliário.

\section{DESENVOLVIMENTO DO PROJETO}

Depois de todo o estudo sobre design de espaços, mobiliário, ergonomia e, também, o estudo da definição da metodologia ideal, é possível dar início ao desenvolvimento do projeto. Aqui está apresentado, de forma explicativa, todas as fases de criação do móvel, desde seu início até a finalização.

\section{FASE 1: ANÁLISE DO PROBLEMA}

Serão aplicadas as perguntas Bonsiepianas (figura 8), propostas por Gui Bonsiepe (1984), onde facilitará o entendimento do problema e dará continuidade aos próximos passos, como está disposto na imagem a seguir. 


\section{Perguntas Bonsiepianas}

Desenvolver um móvel multifuncional, que ora é mesa, ora é cadeira, que seja desmontável e de fácil manuseio, que contribua na qualidade de aprendizagem dos acadêmicos e otimizando o espaço habitado.

PORQUE?

O Programa Estudantil fornece poucas unidades de bancadas que sejam próprias para o estudo e não foi constatado o fornecimento de cadeiras ergonomicamente corretas para o uso prolongado.

COMO?

Utilizando metodologias de projeto que visam auxiliar no decorrer do trabalho e estudando e aplicando os referenciais coletados.

PRA QUEM?

Para os moradores da Casa do Estudante Universitário (CEU).

Figura 8 - Perguntas Bonsiepianas. Fonte: Desenvolvido pela autora com base em Bonsiepe (1984).

\section{FASE 2: TÉCNICAS ANALÍTICAS}

Na fase de técnicas analíticas, de Bonsiepe (1984), é estruturada para entender os produtos similares encontrados no mercado, onde para este projeto será aplicada a análise sincrônica, estrutural e funcional. Depois de aplicadas essas técnicas, será viável fazer averiguações, onde será levantada uma lista de requisitos, para possibilitar ou não, a aplicação destes conceitos analisados no projeto móvel Movi.

A escolha do produto multifuncional ser cadeira e mesa, se dá a partir da verificação do estudo da CEU, onde foi constatado neste trabalho que será relevante a presença de um móvel mesa/ cadeira, ergonomicamente corretos, para otimizar os estudos dos moradores da Casa do Estudante Universitário da UFPel. 
Os móveis constantes nas análises a seguir, foram escoIhidos devido a todos serem assinados por Designers, vendidos no Brasil, e de fácil obtenção através de sites de venda, como por exemplo a Boobam, no qual constam todos os produtos escolhidos. Outros fatores considerados foram a facilidade e forma de montagem, a qualidade dos materiais, e possibilidade do móvel ser mesa/cadeira, o que foi considerado dificultoso pois foi encontrado apenas um modelo.

\section{Análise Sincrônica}

Nesta análise, será possível comparar os 10 produtos do mercado de forma física. Nas figuras 9 e 10 a seguir, vamos analisar com qual material os produtos são compostos, assim como, suas dimensões, o peso total, local de vendas e preço de mercado.

Após a elaboração da análise, foi constatado que na maioria, o nome de cada produto tem ligação direta com a aparência, com a forma de uso, com as cores, ou é apenas o nome do autor/autora (figuras 9 e 10).

Foi percebido que 9 entre 10 dos produtos de encaixe foi optado pelo material de compensado de madeira, alguns sem especificação do tipo de compensado, mas nos números, 5 - 7 - 9 - 10, foi utilizado compensado laminado naval. (figuras 9 e 10).

Os compensados laminados, como explica Lima (2006), são fabricados a partir de várias lâminas de madeira (nobre, não nobre ou mista), uma sobreposta a outra, de modo que cada folha fique com a fibra da madeira no sentido oposto,

Segundo Lima (2006), esse processo de laminação oposta, faz com que o compensado resista mais aos empenamentos, podendo ser utilizado em diversas áreas. Para a colagem, requer o uso de cola branca ou cola fenólica entre as lâminas. A cola fenólica é utilizada no compensado naval, pois ela tem maior resistência a umidade.

O compensado laminado naval, muito utilizado nos produtos analisados acima nas figuras 9 e 10, será a escolha de 


\section{Conjunto infantil Vira e Mexe \\ Designer: Roberta Sá Faustini}

Conjunto multifuncional, vendido em 2 kits, com a mesa grande e duas cadeiras, ou apenas dois módulos pequenos.

Material: Compensado revestido com laminado PET, com cores em azul, amarelo, branco, rosa, vermelho ou verde.

Onde vende: Boobam

Preço: Kit pequeno $R \$ 588,00$ Kit grande $R \$ 2.222,00$

Dimenções: módulo grande $40 \times 80 \times 40 \mathrm{~cm}$

módulos pequenos $35 \times 35 \times 35 \mathrm{~cm}$ cada

Peso: Não especificado

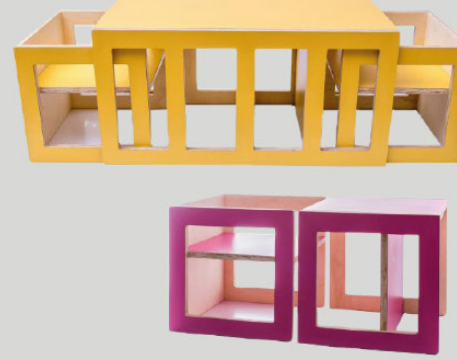

\section{Kit infantil Colmeia}

Designer: Bertha Home

Kit com uma mesa e 2 banquinhos, produto 100\% de encaixe, vem com manual de montagem e um martelo de borracha.

Material: MDF laminado em duas faces nas cores pêssego, azul jeans, mostarda ou cerâmica.

Onde vende: Bertha Home, Boobam

Preço: RS 552,00

Dimenções Mesa: 43×59x59 cm Banco: 22×31×31 cm

Peso total: $9,5 \mathrm{~kg}$

\section{Frida banqueta \\ Designer: Zanocchi \& Starke}

Banqueta totalmente desmontável e apenas um parafuso modelo borboleta para trava. Pelo seu simples sistema de montagem, dispensa o uso de manual de montagem.

Material: base feita de madeira maciça e topo em MDF revestido, cores disponíveis em preto, azul e branco.

Onde vende: Boobam

Preço: 2.990,00

Dimenções: $37 \varnothing \times 43 \mathrm{~cm}$

Peso total: $4,5 \mathrm{~kg}$

\section{Cadeira Plana}

Designer: ZeroMaquina

Conceito "Flat-pack", uma nova versão da famosa cadeira dobráveis. Feita para facilitar o transporte, armazenamento e ocupar pouco espaço. Também em tamanho infantil.

Material: Compensado laminado de madeira de pinus.

Onde vende: ZeroMaquina, Boobam

Preço: de $R \$ 290,00$ a $R \$ 410,00$

Dimenções: $42 \times 78 \times 39 \mathrm{~cm}$

Peso: Não especificado
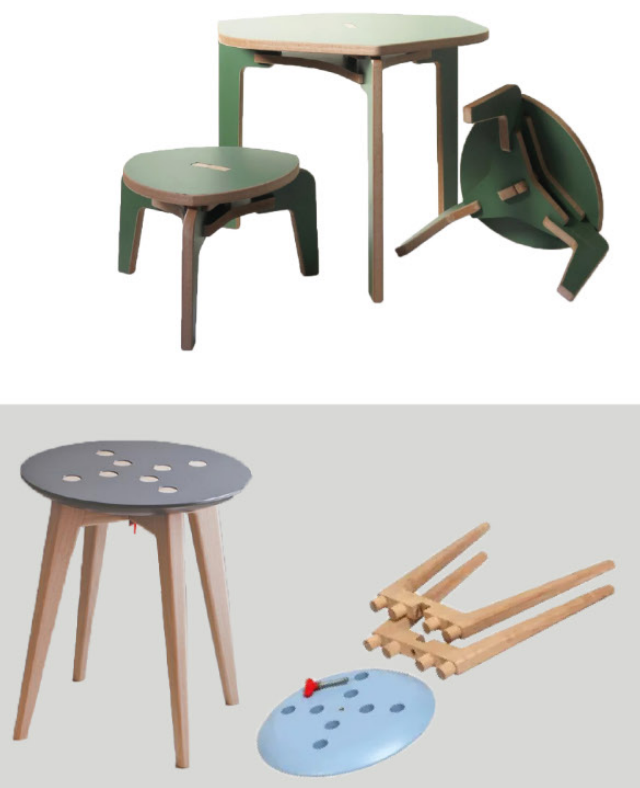

\section{Mesa Lina}

Designer: Lina Maeoca, ZeroMaquina

Mesa estruturada apenas com encaixes, com centro vazado para acoplação do balde, que pode servir de vaso de flôr ou para gelo e bebidas.

Material: Compensado naval, o tampo pode ser formicado.

Onde vende: ZeroMaquina, Boobam

Preço: $\mathrm{R} \$ 1.654,00$

Dimenções: $100 \varnothing / 110 \varnothing / 120 \varnothing \times 75 \mathrm{~cm}$

Peso: Não especificado
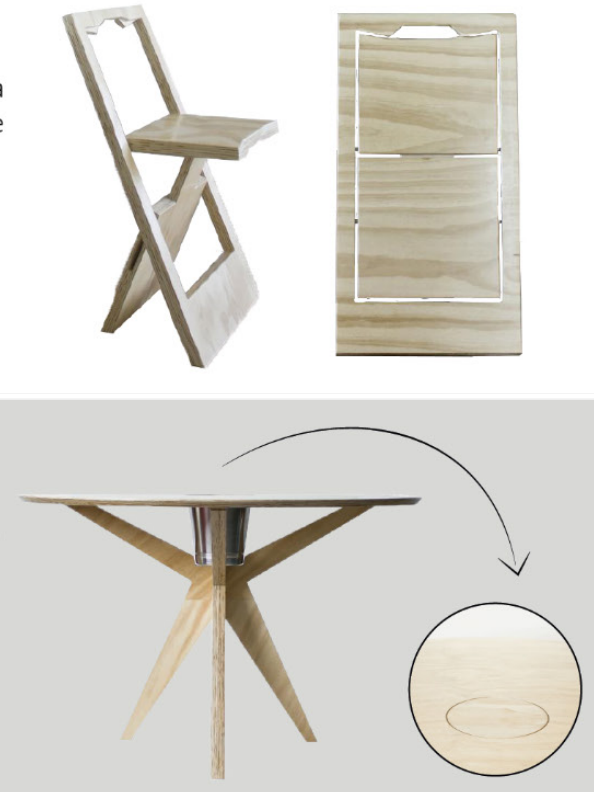

Figura 9 - Análise Sincrônica (produtos 01 ao 05)

Fonte: Elaborado pela autora. 


\section{Conjunto Mesa de Atividades Noos \\ Designer: Noos}

Conjunto infantil desmontável, com 1 mesa de atividades, 1 banco e 1 cadeira com encosto ergonômico para criança.

Material: Laminado de madeira com folha de acabamento em madeira (Jequitibá, Nogueira e Carvalho). Pintura atóxica

Onde vende: Noos, Boobam

Preço: média de $R \$ 2.132,00$ a $R \$ 2.330,00$

Dimenções: mesa $57 \times 50 \times 37 \mathrm{~cm}$, cadeira $45 \times 40 \times 43 \mathrm{~cm}$ e

banco $46 \times 38 \times 20 \mathrm{~cm}$

Peso: mesa $62 \mathrm{~kg}$, cadeira $3,2 \mathrm{~kg}$ e banco $2,2 \mathrm{~kg}$

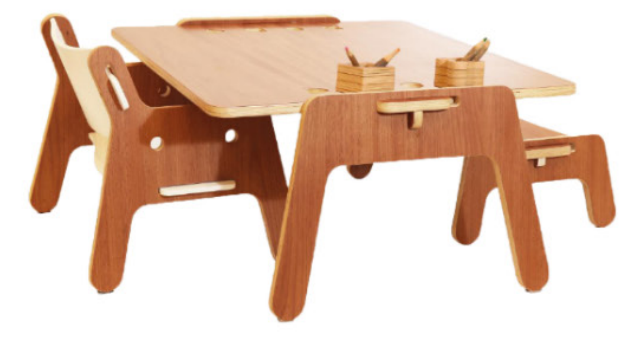

\section{Mesa Plié}

Designer: ZeroMaquina

Pensada na economia de materiais e com conceito encaixe, não é necessário nenhum outro tipo de ferragem para a montagem.

Material: Compensado Naval, o tampo pode ter formicado.

Onde vende: ZeroMaquina, Boobam

Preço: $R$ \$ 4.170,00

Dimenções $240 \times 120 \times 90 \mathrm{~cm}$ podendo ser customizada

Peso total: Não especificado

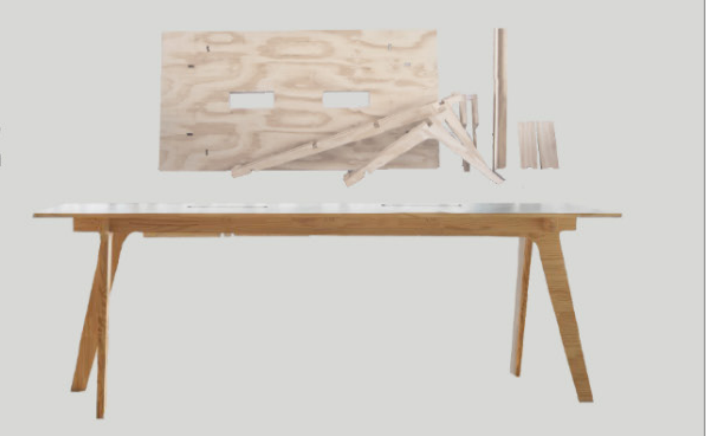

\section{Mesa Infantil Íris}

\section{Designer: Linha Bloom}

Mesa desmontável, feita apenas com 3 peças, nenhuma ferragem e tem montagem super fácil.

Material: Compensado laminado, nas cores branco, cinza, rosa, amarelo, aqua, azul, natural, ou outras cores sob encomenda.

Onde vende: Linha Bloom, Boobam, Extra, Dafiti

Preço: De $R \$ 467,00$ a $R \$ 650,00$

Dimenções: $70 \times 45 \times 70 \mathrm{~cm}$

Peso total: Não especificado

\section{Conjunto mesa Zeit}

Designer: Wood Lock

Conjunto de mesa e banco desmontáveis, disponíveis em 3 tamanhos, para 6, 8 e 10 pessoas.

Material: Compensado Naval feito de reflorestamento,

reaproveitamento das sobras de madeira, acabamentos e verniz feitos artesanalmente.

Onde vende: Wood Lock, Boobam

Preço: de $R \$ 1.300,00$ a $R \$ 2.200,00$

Dimenções: $140 / 180 / 240 \times 75 \times 62 \mathrm{~cm}$

Peso: Não especificado

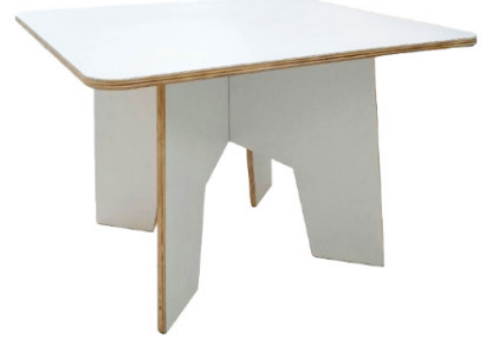

\section{Cadeira baixa Netuno}

\section{Designer: Wood Lock}

A cadeira é montável por encaixes fáceis, sem utilização de ferragens ou ferramentas

Material: Compensado naval de reflorestamento, e sobras reutilizadas em novos materiais, o acabamento é artesanal com verniz de proteção.

Onde vende: Wood Lock, Boobam

Preço: R\$ 739,00

Dimenções: $58 \times 65 \times 70 \mathrm{~cm}$

Peso: Não especificado

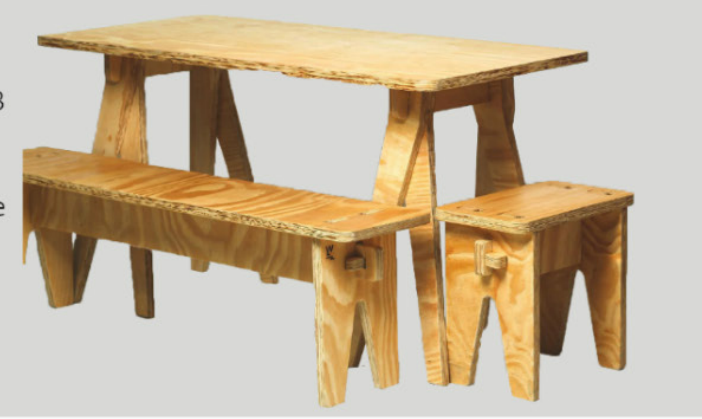

Figura 10- Análise Sincrônica (produtos o6 ao 10) Fonte: Elaborado pela autora 
uso para aplicação no projeto em desenvolvimento. Conforme o site do fabricante Eulide, o compensado Naval tem vantagens, devido a sua alta resistência mecânica a flexão, proteção contra insetos e a umidade, podendo ser usado em ambientes diversos e aumentando a vida útil dos produtos.

\section{Análise Estrutural e Funcional}

Aqui analisamos os mesmos 10 produtos (constantes na tabela 9 e 10) de forma estrutural e funcional. São estudadas as quantidades de peças de cada produto, a técnica construtiva, ou seja, a forma de como são montados, se possui encaixes, ferragens ou cola e, ainda, os tipos de acabamentos, conforme mostram as figuras 11 e 12 a seguir.

A quantidade de peças de cada artefato tem variação, pois há produtos únicos e produtos em conjunto como nos casos do 1, 2, 6 e 9, onde a venda se apresenta em forma de kit (mesa e cadeira/banco).

O produto 1, como não é desmontável, ao todo são 3 peças; o conjunto 2, possui 8 peças em cada cadeira ou mesa, dando o total de 24 peças; O conjunto 6, possui 4 peças em cada cadei$\mathrm{ra} / \mathrm{mesa} / \mathrm{banco}$, mais 2 parafusos do encosto na cadeira, dando um total de 14 peças; O conjunto 9, possui 11 peças na mesa e mais 6 em cada um dos 4 bancos, chegando ao total de 35 peças.

Os produtos 3, 4 e 10 tem uma única função de assento. A banqueta 3 possui apenas 4 peças; A cadeira 4 possui apenas uma, pois não é desmontável; A cadeira 10 possui apenas 5 peças.

Os produtos 5, 7 e 8 tem a função de mesa, alterando a forma de aplicação, podendo ser destinada a mesa de bar, escritório, cozinha ou para atividades em geral. A mesa 5 possui 5 peças; A mesa 7 possui 10 peças e a mesa 8 possui apenas 3 peças. 


\section{Conjunto infantil Vira e Mexe}

As cadeiras encaixam debaixo da mesa

Kit grande: 1 módulo grande +2 módulos pequenos

Kit pequeno: 2 módulos pequenos

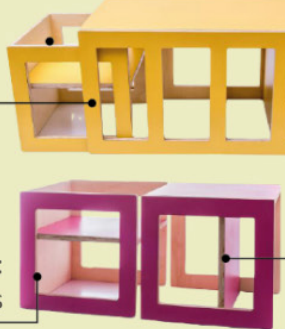

Pode servir de cadeira mesa ou degrau.

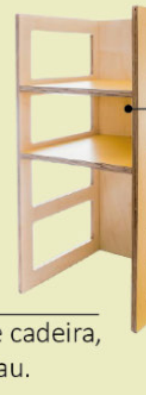

Mesa que pode servir de cadeirão, cadeira ou torre.

O mobiliário tem todos os cantos arredondados, são resistentes e seguros. A montagem das peças é feita com cola especial e não se utiliza mais nenhum tipo de ferragem.

\section{Kit infantil Colmeia

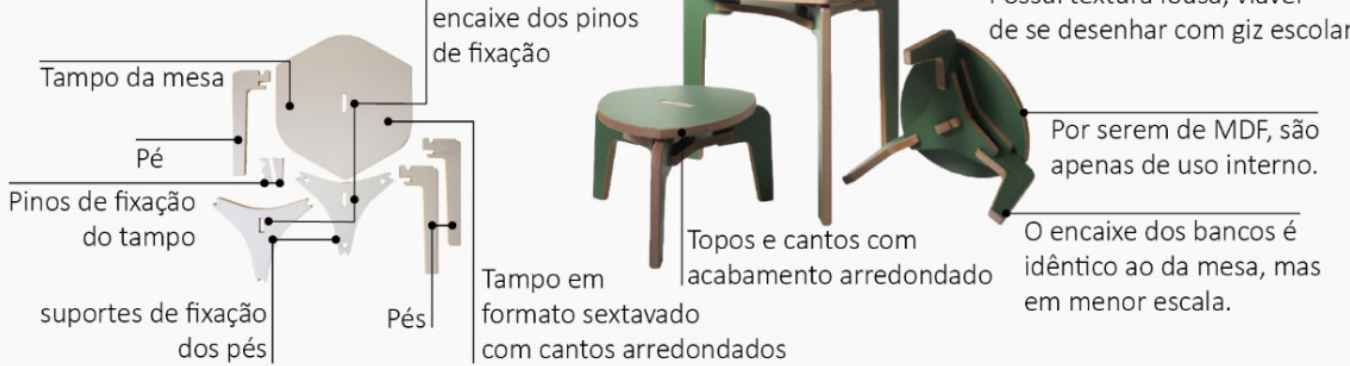

\section{Frida banqueta}
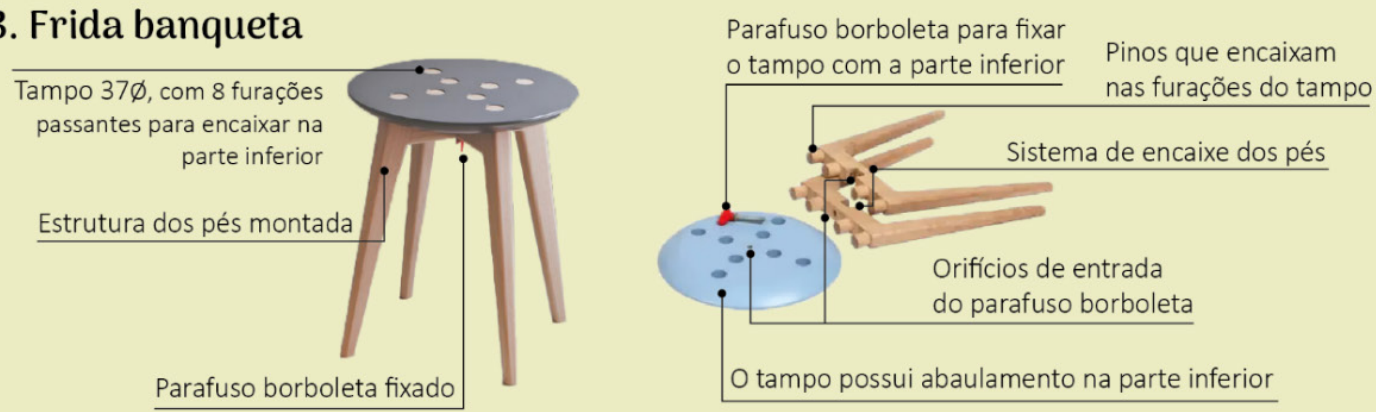

\section{Cadeira Plana}
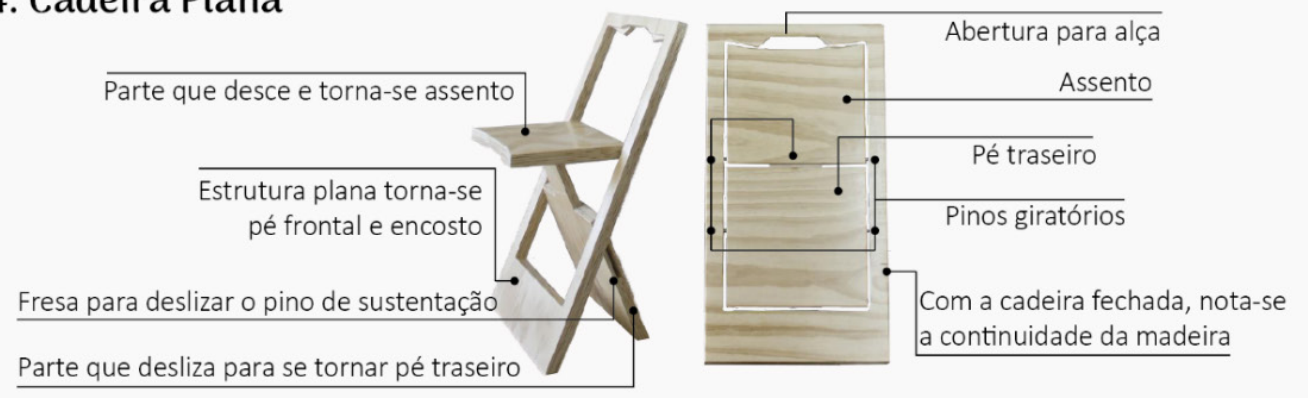

\section{Mesa Lina}
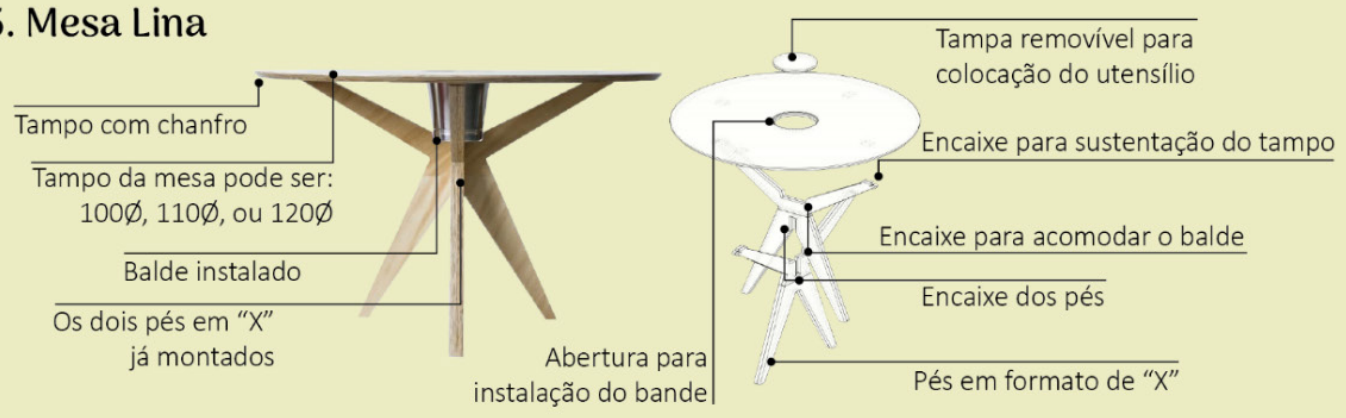

Figura 11 - Análise estrutural e funcional (01 ao 05) Fonte: Elaborado pela autora, com base na pesquisa realizada. 


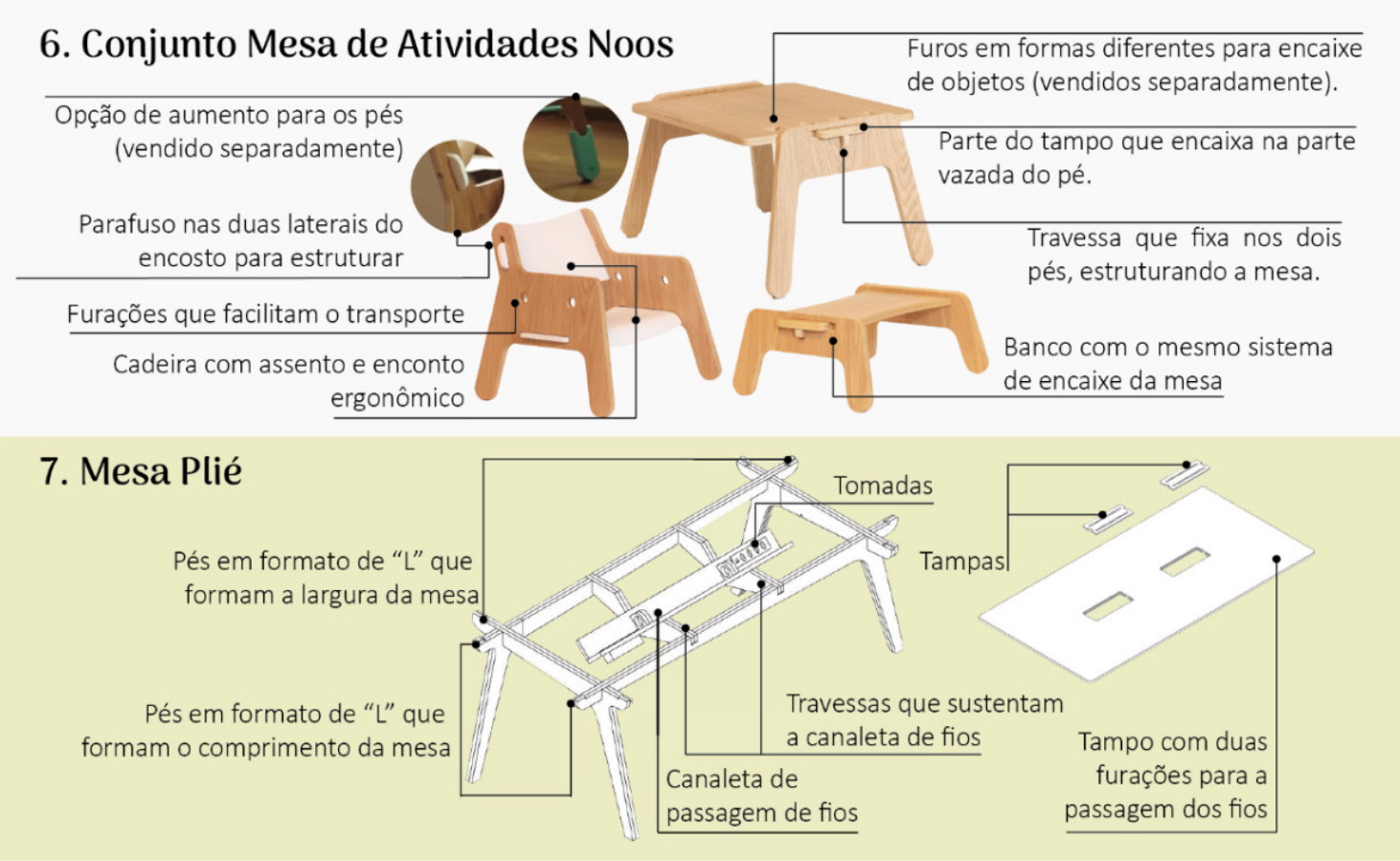

\section{Mesa Infantil Íris}

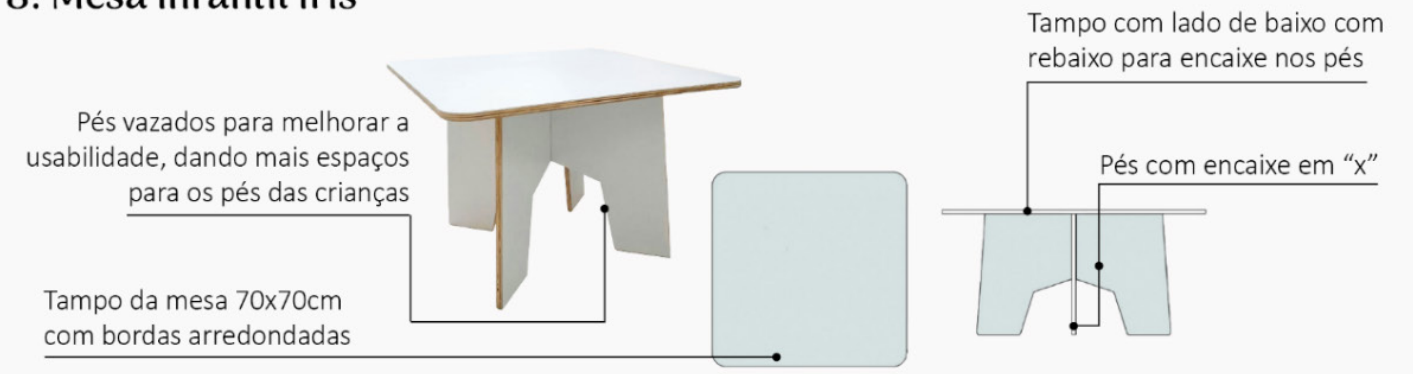

\section{Conjunto mesa Zeit

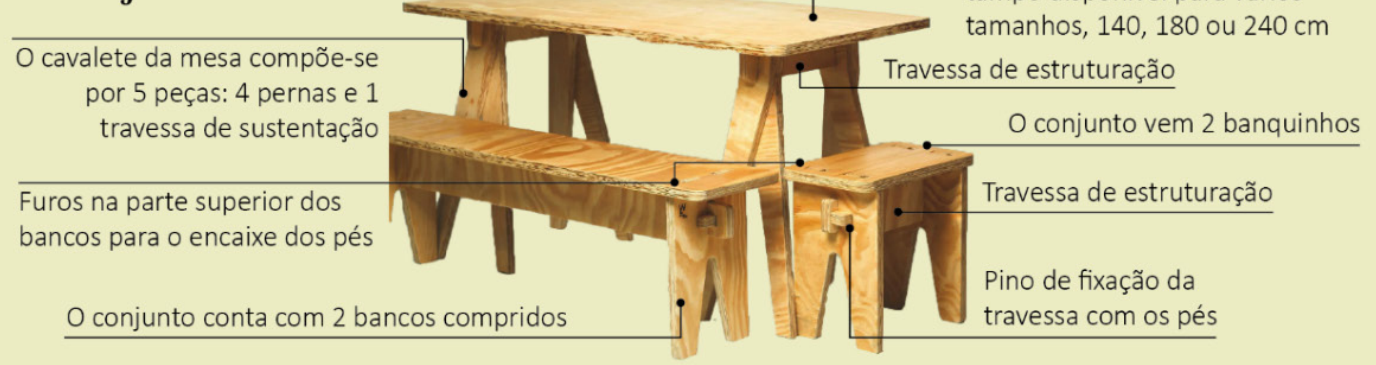

\section{Cadeira baixa Netuno}

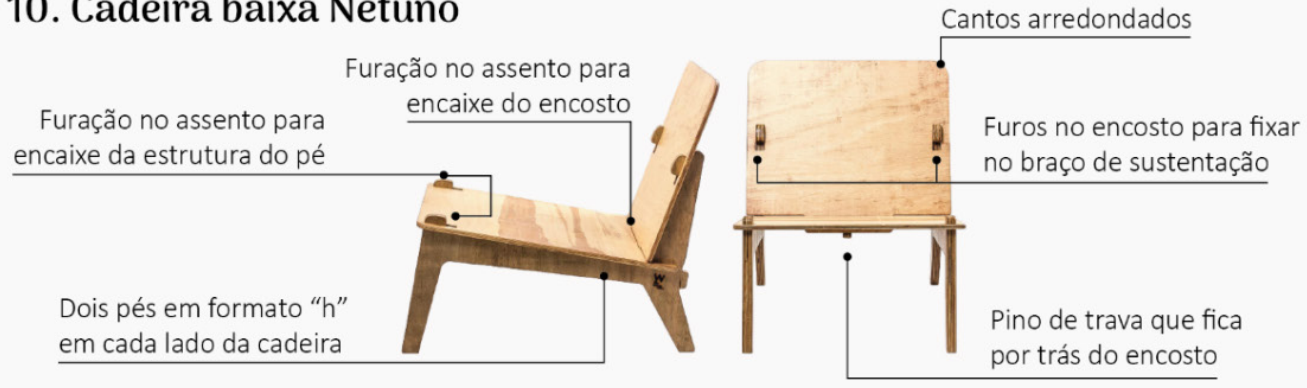




\section{Lista de Requisitos}

Depois de todo esse processo de conhecimento e análises (sincrônicas, estruturais e funcionais) dos produtos em mercado, foi feito um levantamento de requisitos que o projeto deve atingir no final do desenvolvimento (figura 13). Bonsiepe (1984) explica que os requisitos auxiliam o processo projetual em relação as metas a serem alcançadas, como DEVE ser, como PODE ser e como NÃO PODE ser.

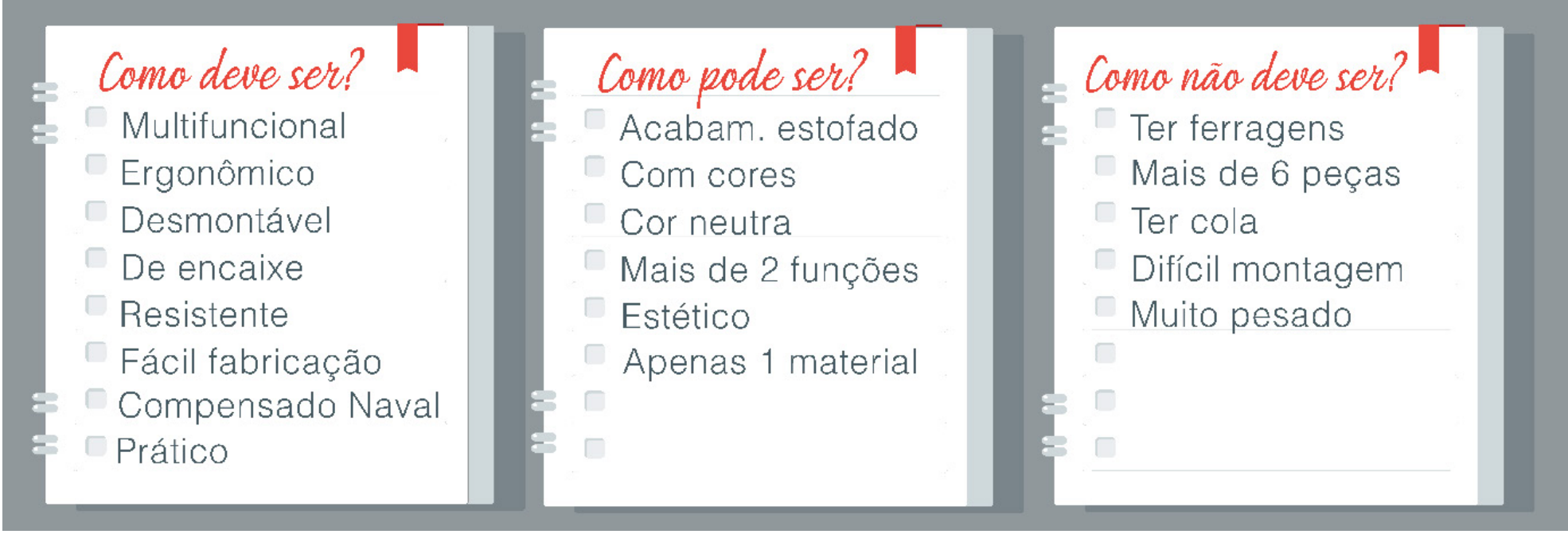

Figura 13 - Lista de requisitos. Fonte: Desenvolvido pela autora.

\section{FASE 3: GERAÇÃO DE ALTERNATIVAS}

Como constatou Löbach (2001), na fase 3 será o início da produção de ideias onde, a partir de todas as análises feitas, será possível dar seguimento ao desenvolvimento do produto e começar a etapa fase de croquis como está demonstrado na figura 14 a seguir.

Foi esboçado tanto os tipos de encaixe, quanto a estruturação dos produtos, para ser possível o entendimento de cada detalhe (figura 14). Esse foi um importante passo para a familiarização da mente com o lápis e papel, e a partir disso, 


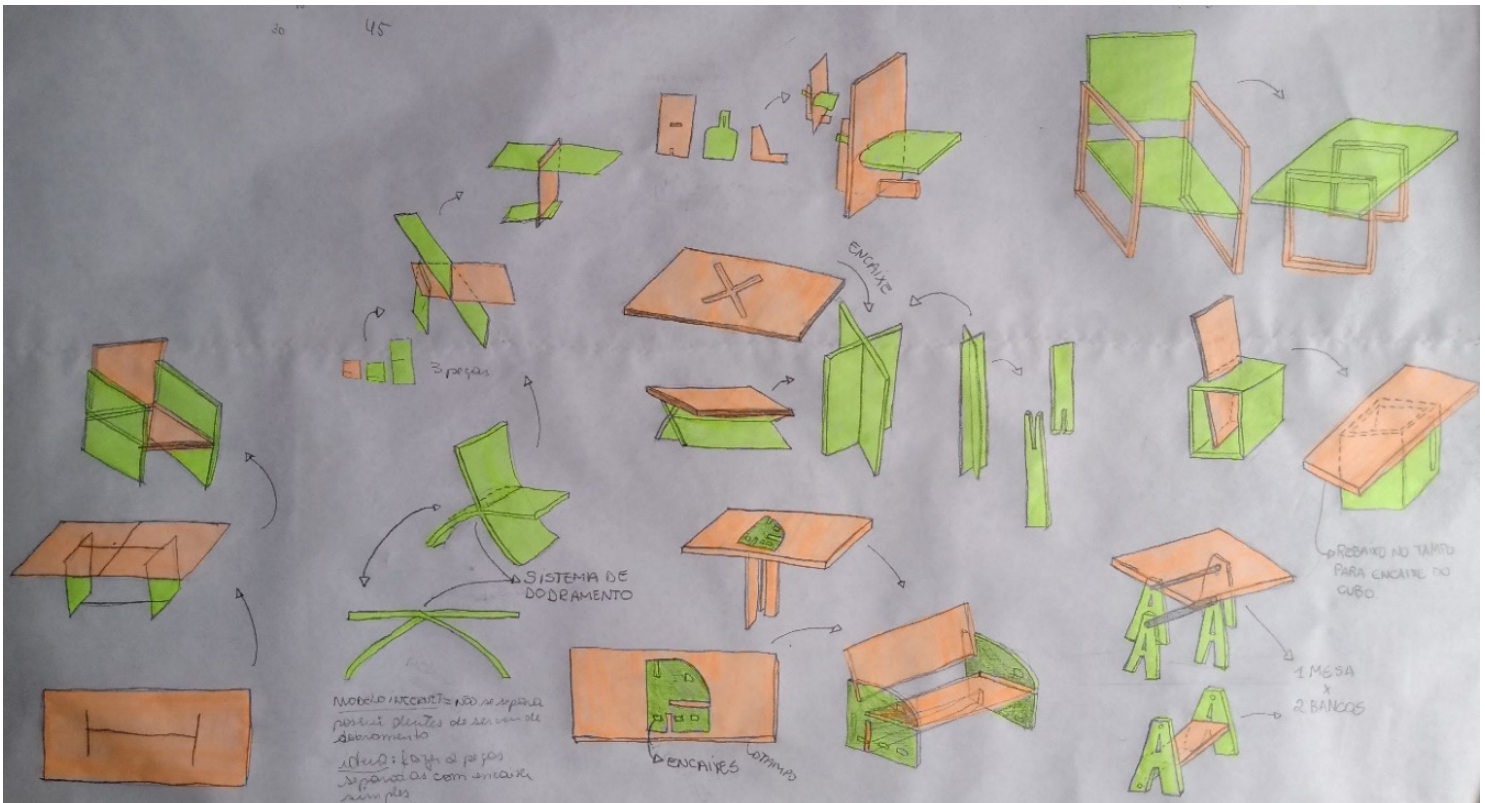

dar vida a criatividade. Depois disso, foram desenhados croquis de formas diferentes para a transformação de cadeira para mesa, tentando trazer os tipos de encaixes já mencionados nas análises realizadas na fase 2 .

Foi dada liberdade para traços criativos, sem muito pensamento no conhecimento acumulado, mas apenas para fluir sem julgamentos. Löbach (2001), diz que, separar o analítico do criativo é importante, pois a preocupação demasiada com o projeto, pode afetar a criatividade e acabar dificultando a geração de alternativas.

\section{FASE 4: AVALIAÇÃO DAS ALTERNATIVAS}

Visto a dificuldade de entender os sistemas de encaixes, as ideias foram passadas para maquetes de papel, sem medidas exatas, apenas para visualizar os possíveis erros e acertos. Em formato de estudos de volumes, no processo de percepção espacial, entender a estrutura das peças e a forma de montagem, ficaram mais explícitas, além de possibilitar a percepção da solidez e estabilidade do móvel.

A partir dos esboços realizados, foram escolhidas três propostas para avaliação e testes em forma de modelos de papel Kraft, as quais apresentam o diferencial de multifuncionalidade ao móvel, alternando entre mesa e cadeira, como mostra a figura 15 abaixo.
Figura 14 - Croquis. Fonte: acervo do autor. 


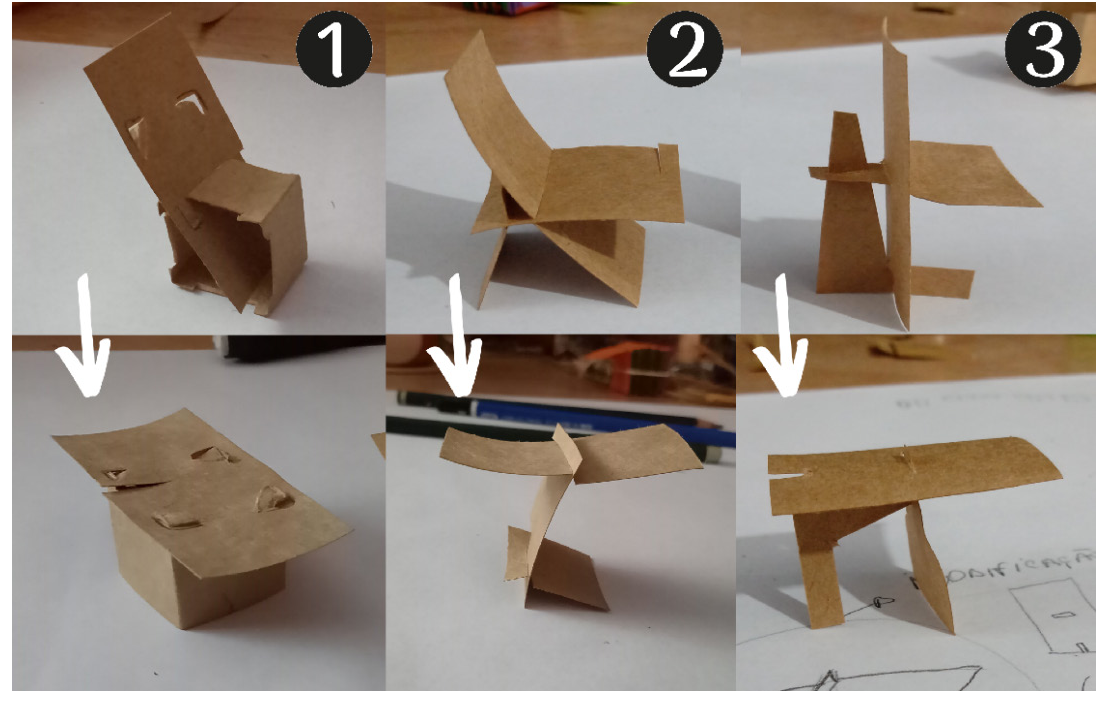

O modelo 1 foi descartado, mesmo a ideia se mostrando criativa e de fácil montagem. O cubo da base, teria que ser fornecido montado, já colado, ou ser disponibilizado desmontado, mas com envio de parafusos ou outros tipos de ferragem para a montagem. Não foi encontrada outra solução para este impasse, logo que a ideia do projeto é que seja feita sem nenhum tipo de ferragem adicional, utilizando apenas encaixes (figura 15).

O modelo 2, apresenta apenas três peças para montagem, com pequenas fendas entre eles para os encaixes. Ele se mostrou deficiente em forma de cadeira, criativa até os primeiros testes observados, porém, em forma de mesa não se mostrou firme e estável. Não foram encontradas soluções para melhorar o encaixe do tampo com o pé e apoio no chão, por isso o descarte (figura 15).

No modelo 3, foi observada uma boa sustentação tanto em forma de cadeira como de mesa. Ela é totalmente desmontável e não necessita de ferragens adicionais, criativa e bem diferente das opções já fornecidas no mercado. Ele também foi o que melhor apresentou soluções de ajustes a partir da ideia inicial, por isso, o modelo 3 foi o escolhido para as próximas fases de criação (figura 15).
Figura 15 - Alternativas escolhidas para a avaliação. Fonte: Acervo do autor. 


\section{FASE 5: REALIZAÇÃO DA SOLUÇÃO DO PROBLEMA}

A fase 5 é a determinação do produto, em questão de estrutura, dimensões e aperfeiçoamento de detalhes finais. Conforme disposto anteriormente, o modelo 3 (figura 15) foi escoIhido para o processo final, onde vamos aprimorar e projetar um mobiliário dentro dos objetivos esperados neste projeto.

Na figura 16 a seguir, é possível visualizar 3 imagens, " $A$ " mostra as peças individualmente, " $\mathrm{B}$ " as peças em modo cadeira, e "C" em modo mesa. Desta maneira, podemos observar a função que cada peça apresenta, denominadas em "a", "b", "c". A peça "a" tem a finalidade de ser tampo de mesa e encosto da cadeira; "b" tem função de base tanto para mesa ou cadeira; e a utilidade de "c" é servir de assento e também de pé lateral da mesa. Essas peças possibilitam a multifuncionalidade do móvel que ora é cadeira e ora é mesa, como mostra na figura 16.
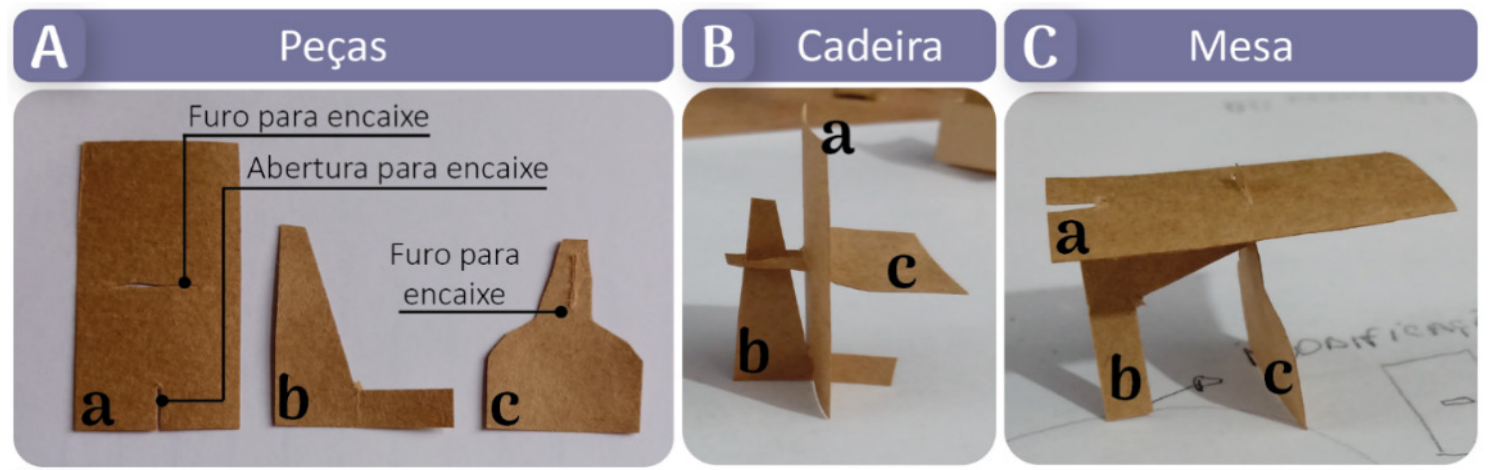

a tampo da mesa e encosto da cadeira

b estrutura base para mesa e cadeira

C assento da cadeira e pé lateral da mesa
Figura 16- Disposição das peças do modelo escolhido na fase 4. Fonte: Elaborado pela autora.

Observando o estudo das peças, o assento (figura 16B) correspondido pela peça " $c$ ", está com a estrutura pouco estável, e não se adapta ao encosto devido a sua curvatura, devendo, por esse motivo, ser modificado. A peça " $c$ " deverá ter alteração na parte do furo de encaixe, pois se nota uma difi- 
culdade no momento de montagem da cadeira (figura 16B).

Deverá ter mudança na localização da peça "c" (figura 16C) pois se encontra centralizado com tampo da mesa, isso dificulta a disposição das pernas do usuário. Foi verificado que a peça "a" precisa de aprimoramento no encaixe com a peça "b", para melhorar a estabilidade.

Após uma série de aprimoramentos no projeto, com erros e acertos, ajustes nos encaixes e na estrutura das peças, chegou-se a uma solução viável conforme está apresentado na imagem a seguir.

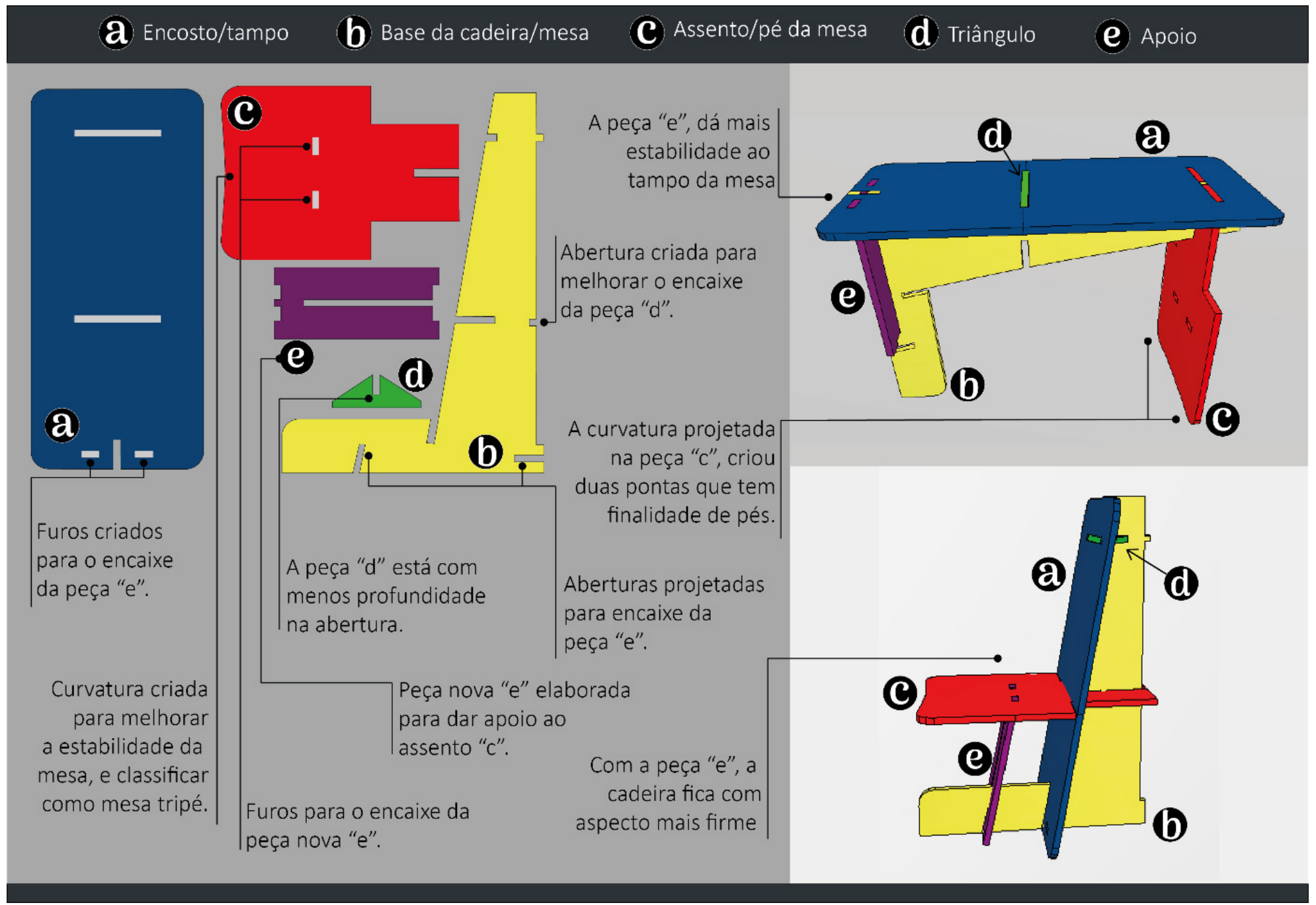

Figura 17 - Aprimoramento do projeto.

Fonte: Elaborado pela autora. 
Na figura 17 acima, podemos notar que foram criadas duas novas peças " $d$ " e "e" para estruturação do móvel, elas são responsáveis por dar firmeza e estabilidade ao projeto, e, com isso, também foram criados novos encaixes para união das peças.

Houve modificação na curvatura da peça " $c$ " e melhorou a estabilidade da estruturação. Essa curvatura agora está na outra extremidade, dando melhor equilíbrio quando posicionada no chão, em modo mesa, dando classificação de uma mesa de 3 sustentos. Também na peça " $c$ ", foi modificada a parte de encaixe, onde antes era um furo, agora é uma abertura, com isso melhorou a forma de montagem (figura 17).

Foi criado na peça "a" um novo furo, resolvendo o problema do componente " $c$ ", enquanto mesa, que se encontrava localizado no centro, o que dificultava o acesso das pernas. Com essa mudança, temos um vão livre embaixo da mesa para os pés (figura 17).

Observamos que alguns cantos das peças "a", "b" e "c", foram arredondados, tanto para melhorar a estética suavizando a aparência do móvel, quanto para evitar lesões em possíveis acidentes domésticos (figura 17).

Com estes ajustes citados acima, sobre a estrutura e funcionalidade dos encaixes das peças, podemos dar finalização ao processo. O próximo passo será de conferência das medidas ergonômicas e antropométricas que será visto a seguir.

A avaliação da ergonomia será aplicada diretamente sobre as imagens do móvel, projetadas e humanizadas através de um software de projeção 3D. A figura 18 a seguir, mostra a estação de trabalho em vista superior, podendo assim, ser observada as medidas do tampo da mesa e do assento.

A medida A representa a profundidade na mesa, que é a área da superfície de trabalho. Esta zona deve ser o suficiente para acomodar papeis, cadernos e/ou notebook, onde Panero e Zelnik (2008) afirmam que pode ter de 40,6 à 50,8cm. Para se ter um intermédio, foi definido que $48 \mathrm{~cm}$ são suficientes para acomodar as atividades de estudo (figura 18). 


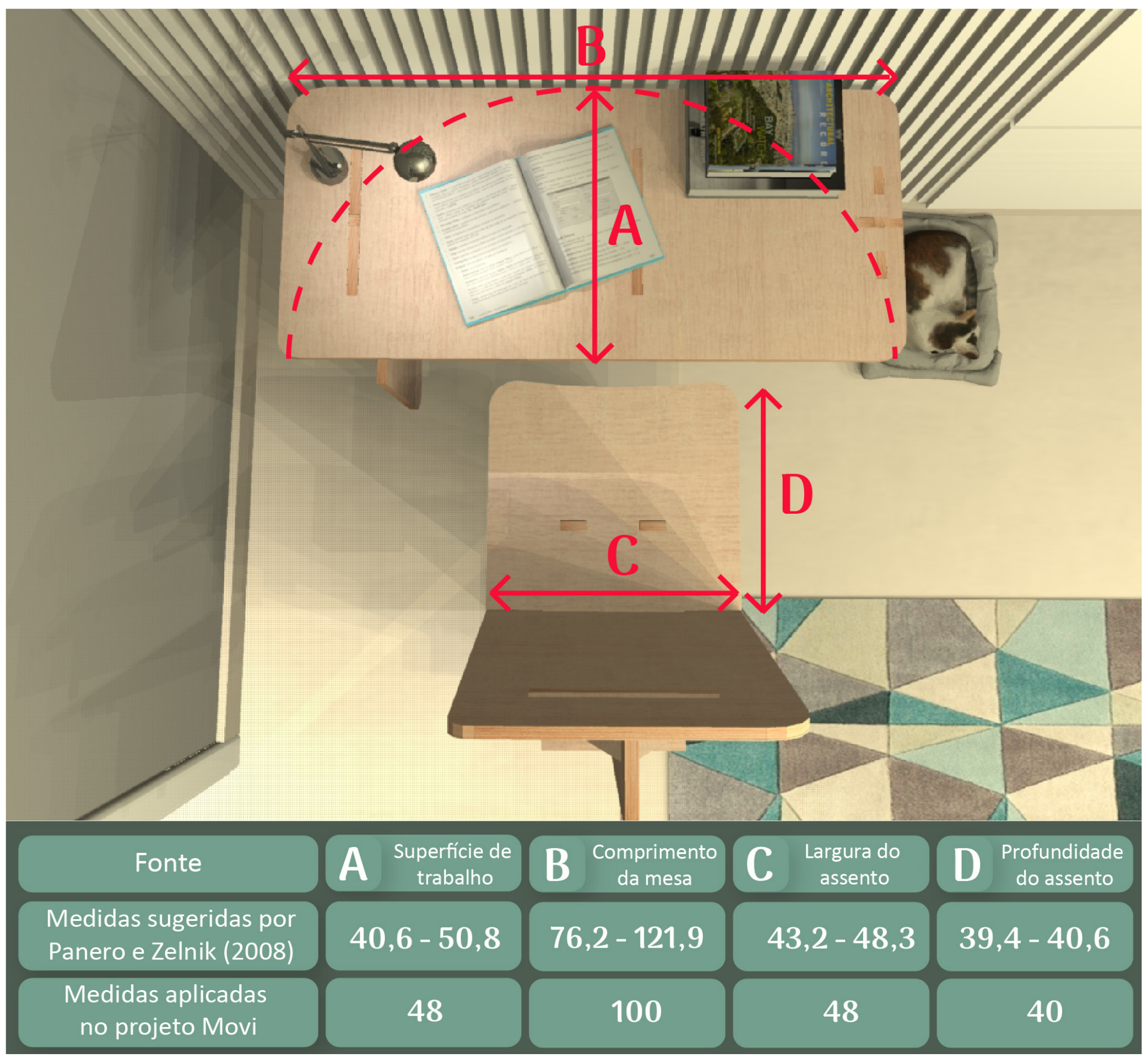

Figura 18 - Aplicação ergonômica na estação de trabalho, vista superior (cm). Fonte: Desenvolvido pela autora a partir da referência de Panero e Zelnik (2008).

A letra B condiz com o comprimento da mesa, que está aplicada a medida de $100 \mathrm{~cm}$. Panero e Zelnik (2008) ressaltam que a medida de $76,2 \mathrm{~cm}$ é o espaço individual mínimo e o necessário para possibilitar o apoio dos cotovelos sobre a mesa (figura 18). 
A zona C delimita a largura do assento, onde Panero e Zelnik (2008) indicam que pode ter a variação de 43,2 à 48,3cm. Para adequar a maior variação de percentis, foi aplicada na área $C$, a medida de $48 \mathrm{~cm}$, a qual se utiliza a maior dimensão de forma a atender a maioria dos usuários (figura 18).

O parâmetro antropométrico da nádega sulco poplíteo de 43,7cm (percentil 5), segundo Panero e Zelnik (2008), é a referência para determinação da profundidade do assento, visto que essa dimensão deve ser menor que a medida corporal indicada.

De acordo com as tabelas apresentadas por Panero e Zelnik (2008), é ideal utilizar o espaço compreendido entre 39,4 à 40,6cm, com isso, a profundidade do assento foi definida em $40 \mathrm{~cm}$, de forma que acomode a maioria dos usuários, visto que serão atendidos os percentis de 5 a 95\% (figura 18).

Constata-se que as medidas A, B, C e D se enquadram entre os percentis 5 e 95, indicados por Panero e zelnik (2008), pois atendem um grande número de usuários visto as verificações dos parâmetros antropométricas estudados (figura 18).

A figura 19 a seguir, retrata as medidas antropométricas aplicadas na estação de trabalho em vista lateral, e pode ser visualizada as dimensões de altura da mesa e do assento, e também da angulação do encosto.

$A$ medida $E$, refere-se à altura da mesa contando com a espessura do tampo, a qual Panero e Zelnik (2008) dizem que essa deve ter entre 71,1 e 76,2cm, dependendo da cadeira utilizada para estipular a medida final. No projeto Movi foi aplicado para $\mathrm{E}$, a altura de $73 \mathrm{~cm}$.

A altura do assento, representada pela letra $F$, tem as medidas de 44,2 e 47,8cm sugeridas por Panero e Zelnik (2008). Para o móvel Movi, adequamos um intermédio entre as duas, ficando definida a dimensão de $45 \mathrm{~cm}$, pois abrange o maior número de pessoas altas, visto que as mais baixas podem utilizar um descanso de pés (figura 19).

A medida $G$, determina a diferença de altura entre a mesa e o assento, sendo essa dimensão estipulada por Panero e Zelnik (2008) entre 27,1 e 29,7cm. Determinamos G em $28 \mathrm{~cm}$, 


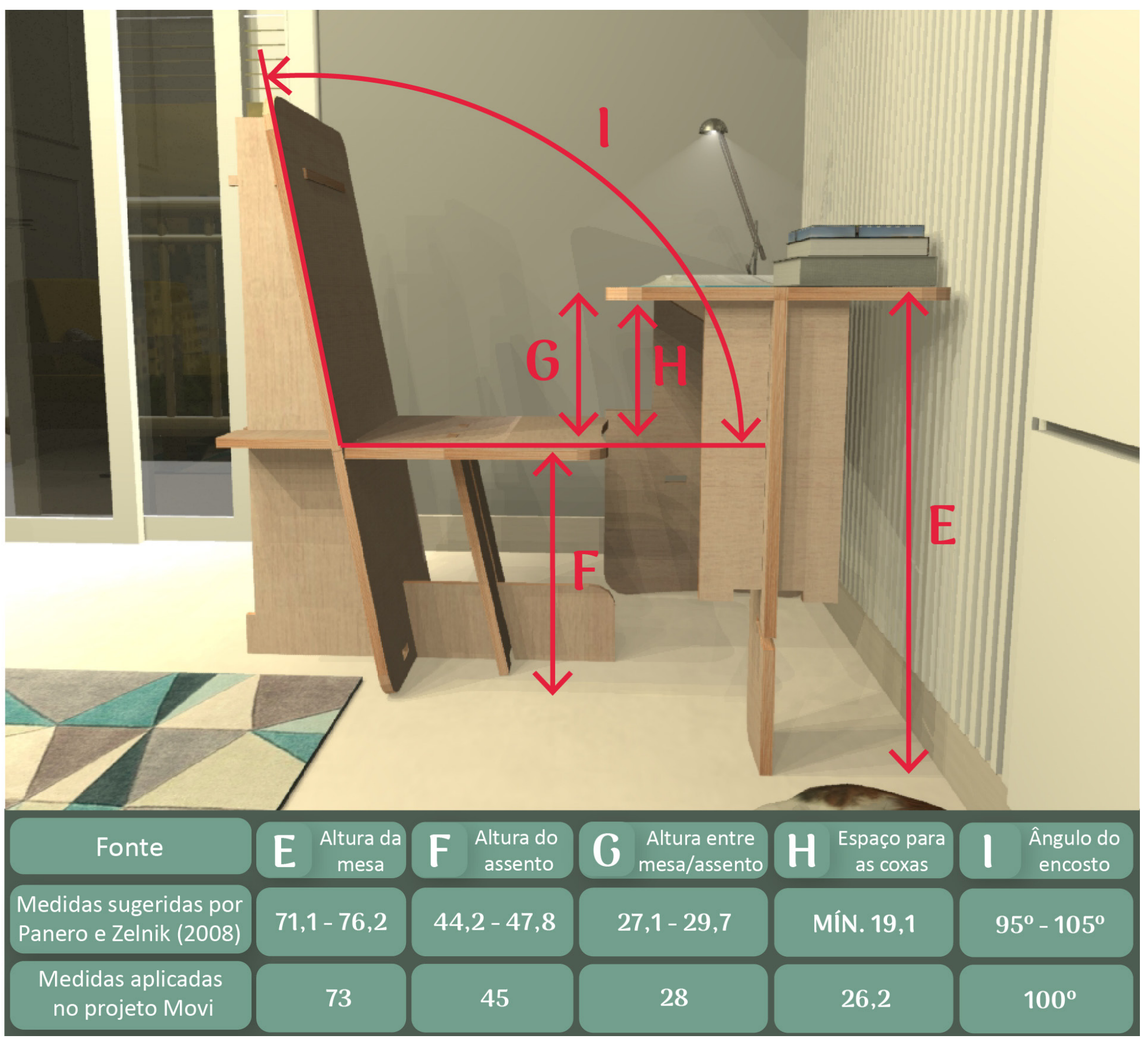

Figura 19 - Aplicação ergonômica na estação de trabalho em vista lateral (cm). Fonte: Criada pela autora a partir da referência de Panero e Zelnik (2008).

que subtraindo as medidas E e F, darão os $28 \mathrm{~cm}$ aplicados, o que origina o espaço para as coxas de $26,2 \mathrm{~cm}$ com a retirada da espessura do tampo de $18 \mathrm{~mm}$ (figura 19).

E por fim, a medida I retrata a angulação do encosto em relação ao assento, que Panero e Zelnik (2008) estimam que 
o ideal será em torno de $95^{\circ}$ à $105^{\circ}$. Essa angulação convém para melhor acomodação do usuário, logo, foi determinado ao projeto, um ângulo médio de $100^{\circ}$ (figura 19).

Observou-se que na figura 43, as medidas E, F, G, H e I, de adequam aos parâmetros antropométricos estudados, agregando a maior margem de usuários possíveis.

A imagem 20 a seguir, é a demonstração de uso do mobiliário, através de maquete e utilizando o boneco antropométrico em escala 1:6 nas possíveis posições e modos de uso.

Dentre as três categorias que caracterizam as funções básicas do produto, impostas por Löbach (2001), foi verificada que a característica de prevalência do móvel Movi é a Função Prática. O móvel Movi tem relação direta com o uso, é adequado a partir das medidas ergonômicas, da facilidade de uso e montagem, da segurança e da eficiência multifuncional.

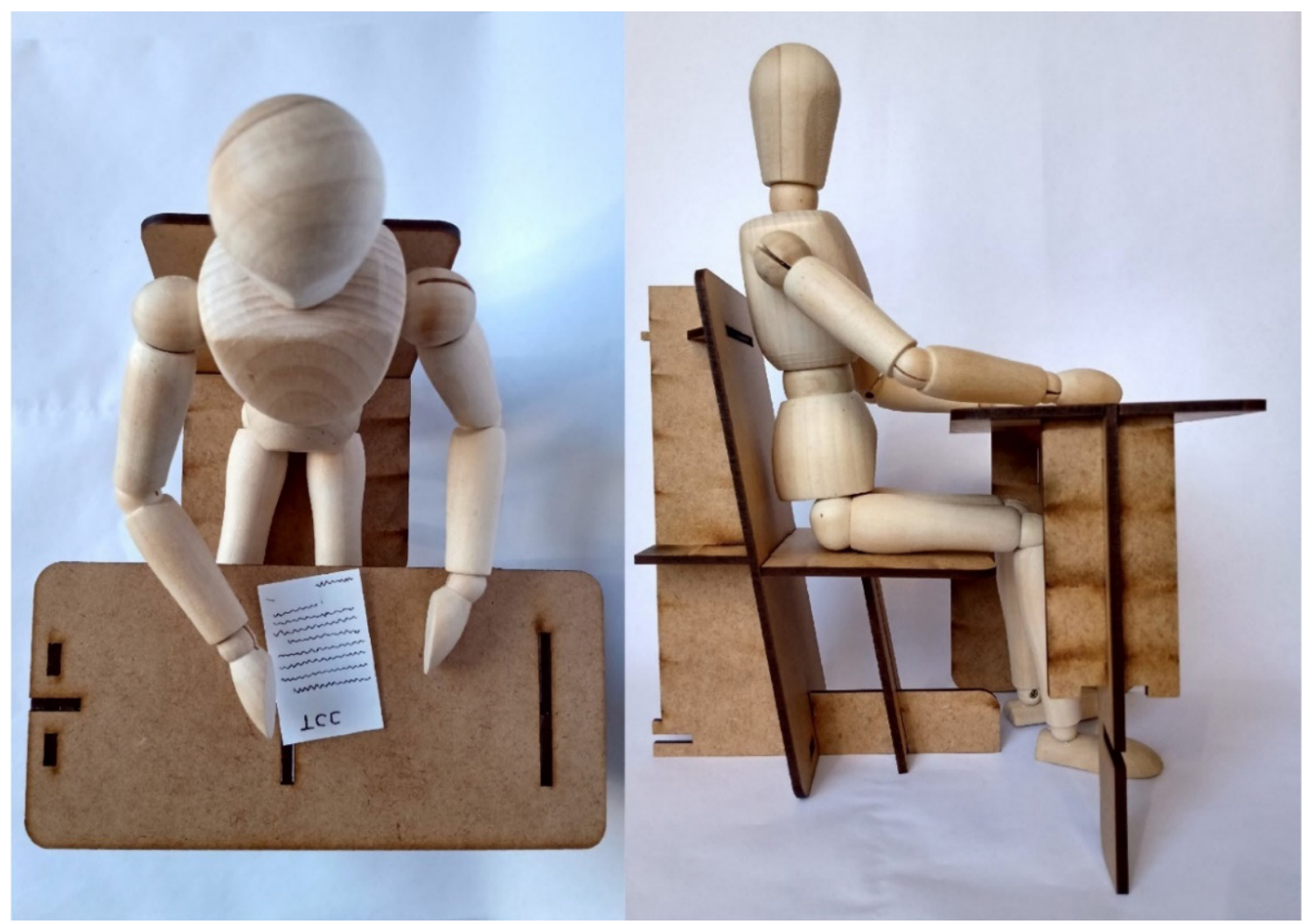

Figura 20 - Maquete Móvel Movi em modo de uso. Fonte: Desenvolvido pela autora. 
O nome "Movi" escolhido para este projeto, está diretamente ligado ao que o móvel representa fisicamente, deriva-se da sua disposição e mudanças dos componentes, gerando um (movi)mento para a troca das peças de mesa para cadeira.

Após a verificação ergonômica e da função do móvel, as medidas técnicas foram conferidas e determinadas. Com a disponibilidade das plantas da CEU, é possível fazer a aplicação virtual do móvel Movi no local, através de um software de 3D, como está apresentado na figura a seguir.

A figura 21, monstra o Movi aplicado na área de trabaIho, com vista distante para observar o entorno de possíveis zonas de socialização.

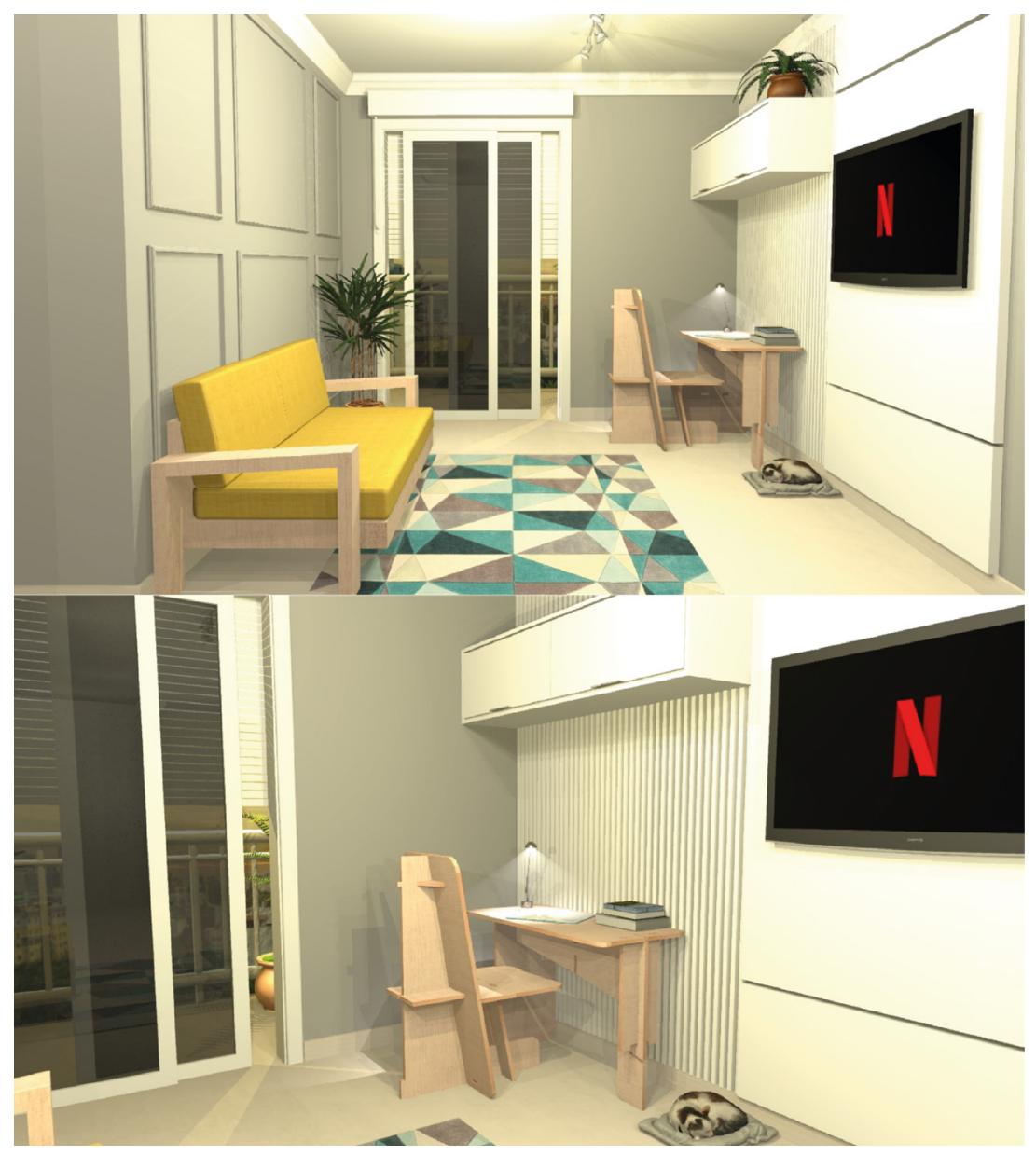

Figura 21 - Móvel Movi com vista da sala. Fonte: autora. 
Aplicação opcional do móvel, podendo ser utilizada tanto como mesa de trabalho em períodos de estudos e, como cadeira de descanso em momentos de lazer e/ou férias, conforme observamos na figura 22.

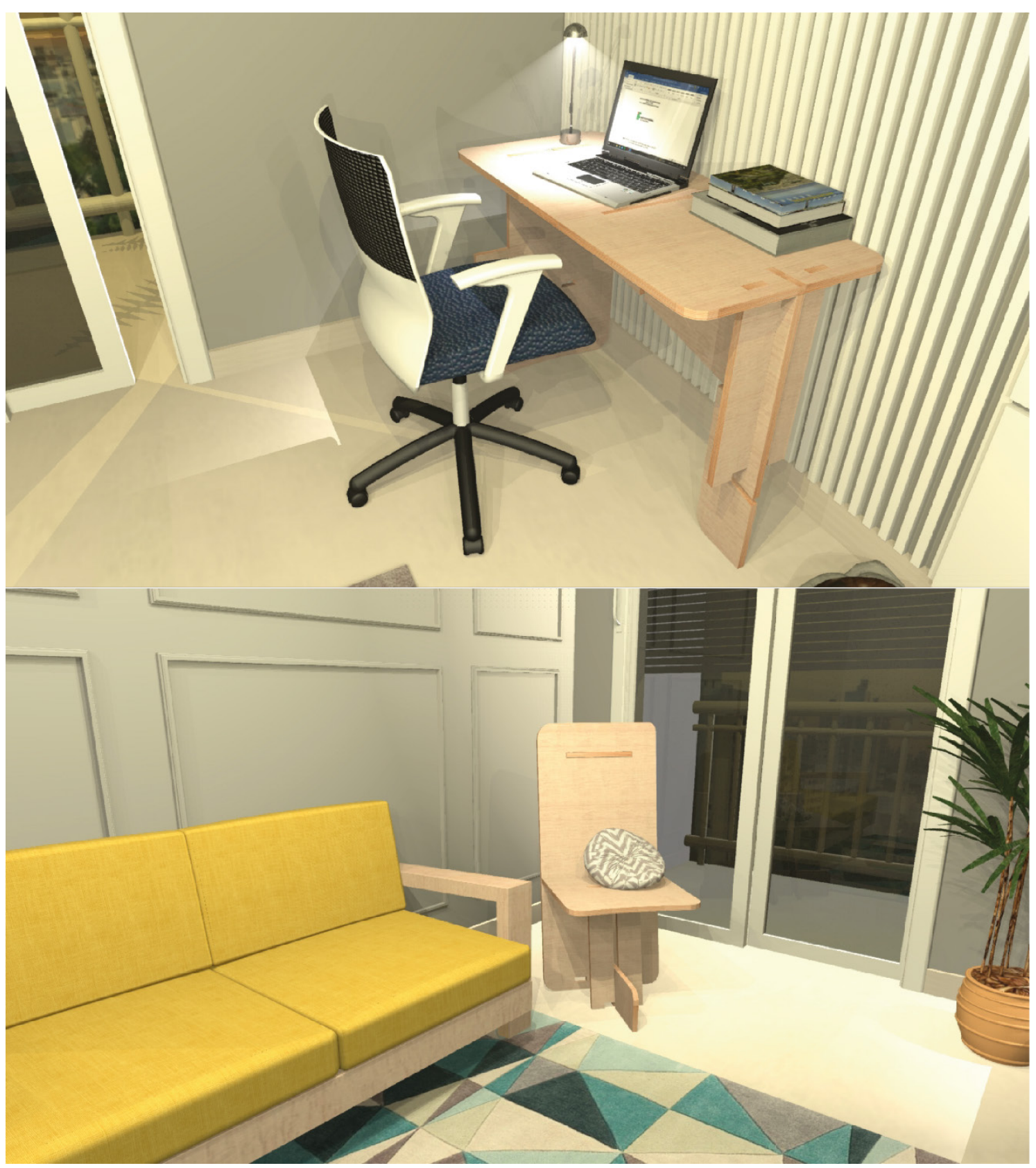

Figura 22 - Móvel Movi com diferentes montagens. Fonte: Projetado pela autora. 
Ambientes com dimensões mínimas, e/ou compartilhado com várias pessoas, necessitam de um móvel prático, funcional, e que execute mais de uma função. A Movi é uma solução para relação deste ambiente. A seguir, a figura 23 mostra a aplicação das zonas pessoais na CEU, podendo ser observado se os limites são respeitados.

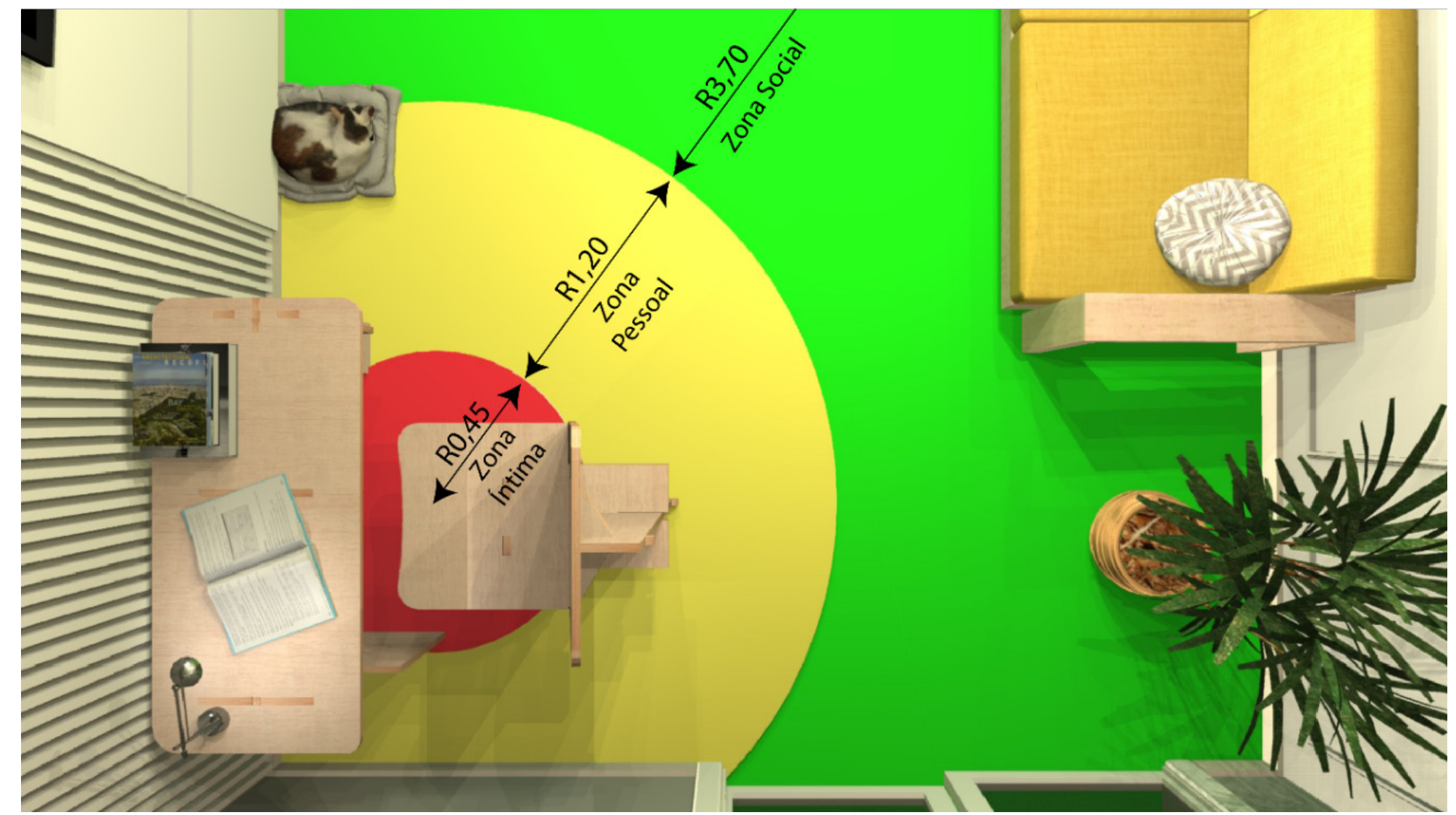

Aplicando esse zoneamento de espaços pessoais na CEU

Figura 23 - Aplicação das zonas pessoais no ambiente CEU (mts). Fonte: Autora. (figura 23), observa-se que a zona intima (região vermelha) da área de trabalho do móvel Movi, está totalmente isolada dos móveis de convívio social, como sofás, mesas e etc. Esse distanciamento é importante pois pode resultar num certo desconforto com a invasão desse espaço por contato físico de outra pessoa. 
Após todo o desenvolvimento do processo de criação do projeto, é chegado o momento de analisar todas as informações, retomando a lista de requisitos retratado anteriormente. A figura 24 representa a verificação dos requisitos alcançados e não alcançados.

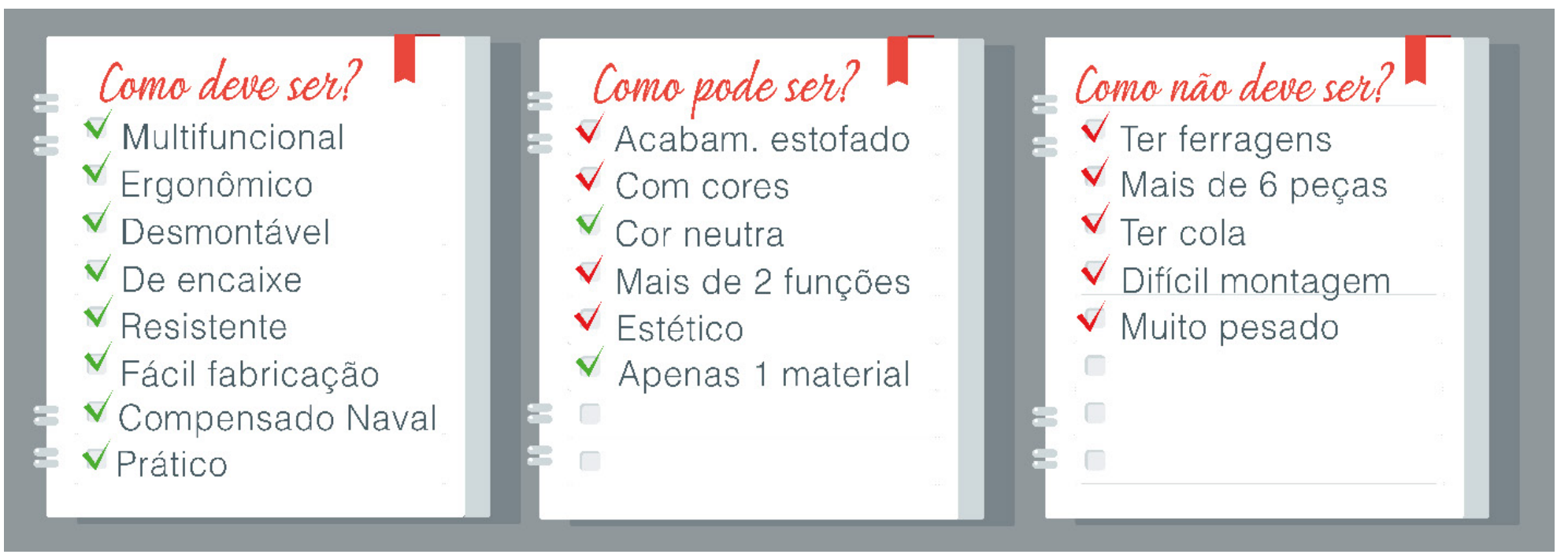

Figura 24 - Verificação de requisitos. Fonte: Desenvolvido pela autora.

Na lista de "como deve ser" todos os requisitos foram alcançados, o móvel é multifuncional, pois tem função mesa e cadeira; é ergonômico pois foram aplicadas as medidas antropométricas do referencial teórico; é desmontável e de encaixe; é resistente pois foram aplicadas as equações de resistência do material; fácil e rápida fabricação, pois é feito de apenas um material e não necessita de montagem na indústria; é projetado para ser usado compensado naval $18 \mathrm{~mm}$ devido sua resistência; e tem função prática, pois é ligada diretamente ao uso.

A lista de "como pode ser" foi aplicada a opção de apenas um material, por conta da fácil industrialização, e a cor neutra foi utilizada para valorizar a cor natural do material. Já na lista "como não deve ser" nenhum requisito foi alcançado, assim como se esperava do projeto. 


\section{CONSIDERAÇÕES FINAIS}

Antes de concluirmos pensando no que foi desenvolvido no contexto teórico, é necessário salientar que o contexto deste trabalho foi conduzido durante a pandemia da Covid-19 que se estendeu durante os anos 2020 e 2021, para então pensarmos no que efetivamente foi produzido. Saber a necessidade de estudantes da CEU, vai além de uma estrutura teórica de algumas décadas atrás, portanto se faz necessários mais estudos que possam conversar com o que realmente os estudantes precisam, para que se realize produtos mais apropriados a suas demandas. No entanto, não pode ser descartável toda sustentação teórica que aqui foi apresentada. São estudos com alicerce, que contribuem para o entendimento das necessidades de moradores de espaços reduzidos, seja em âmbito ergonômico ou funcional, ora também demandas de nossa própria sociedade.

Por conseguinte, além do retrato contextual abordado inicialmente, é necessário trazer pontos para que possamos avançar com esta pesquisa e área. Ainda se faz necessário a entrevista e testes de uso do móvel Movi com discentes da Universidade para atingir as demandas enquanto estudantes residentes da CEU. Que este trabalho possa contribuir para um arcabouço teórico científico de qualidade para sustentar futuras pesquisas que possam emergir deste tipo de modalidade de móveis.

É necessário pensarmos cada vez mais no que a área do Design pode proporcionar para as próximas gerações, principalmente em aspectos que possam contribuir a uma melhor qualidade de vida, seja no trabalho, seja em casa ou em momentos, como o que vivemos, com essa ressignificação do trabalho dentro de nossas casas (homeoffice). Não sabemos quando poderemos ser acometidos por outras pandemias, por exemplo. Ter espaço para além de trabalhar e estudar, mas que se for para fazê-los, que seja da forma mais confortável possível, e que possa ser ressignificado para que possamos ter mais espaço para nós mesmos, mais espaço para que possamos respirar e nos conectarmos conosco mesmo. 


\section{REFERÊNCIAS BIBLIOGRÁFICAS}

BONSIEPE, Gui. KELLNER, Petra; POESSNECKER, Holger. Metodologia experimental: desenho industrial. Brasília: CNPQ, 1984.

CHING, Francis. D. K. Arquitetura de interiores ilustrada. Porto Alegre, RS: Editora Bookman, 2013.

CORRÊA, Larissa Rodrigues de Sousa. “Design de interiores: proposta de projeto para um ambiente residencial de medidas mínimas permitidas pela legislação". 128 f. Monografia (Graduação) Universidade Federal de Pernambuco, Caruaru, 2013.

EULIDE. Compensado Multilaminado, [s.a].

Disponível em: http://www.eulide.com.br/ produto.php?cat=1. Acesso em: 26 jul. 2021.

FOLZ, Rosana Rita. Mobiliário na habitação popular. 2003. $240 \mathrm{f}$. Tese de Doutorado Universidade de São Paulo, São Paulo, 2003.

GIBBS, Jenny. Design de interiores: guia útil para estudantes e profissionais. $1^{\mathrm{a}}$. ed. São Paulo: Brasil: Gustavo Gilli, 2010.

GOETTEMS, Renata Franceschet. Moradia estudantil da UFSC: um estudo sobre as relações entre o ambiente e os moradores. 2012. 188f. Dissertação (mestrado)

- Universidade Federal de Santa Catarina, Centro Tecnológico. Programa de Pós-Graduação em Arquitetura e Urbanismo. Disponível em: https://repositorio.ufsc.br/ handle/123456789/100726 Acesso em: 10 jul. 2021.

IIDA, Itiro. Ergonomia Projeto e Produção. $2^{\mathrm{a}}$. ed. São Paulo: Edgard Blücher Ltda, 2005. 
LIMA, Marco Antonio Magalhães. Introdução aos

Materiais e Processos para Designers, Rio de

Janeiro: Editora Ciência Moderna Ltda., 2006.

LÖBACH, Bernd. Design industrial: bases para

a configuração de produtos industriais. São

Paulo, SP: Editora Edgard Blücher Ltda, 2001.

PANERO, Julius; ZELNIK, Martin. Dimensionamento

humano para espaços interiores. $1^{\mathrm{a}}$. ed.

Barcelona: Editora Gustavo Gili, 2008.

PEZZINI, Marina; ELY, Vera. Usabilidade de Armários Modulados em Apartamentos Reduzidos. Design e

Tecnologia. v.1, n. 01, p. 13, 2010. Disponível em: https://doi. org/10.23972/det2010iss01 pp15-27 Acesso em: 21 nov. 2019.

TOLEDO, Patrícia de Moura e Silva. 0 design

de interiores em hostels: manifestações da

individualidade em quartos compartilhados de

hostel. 2017. 23f. Dissertação. (Mestrado em Ambiente

Construído) - Universidade Federal de Juiz de Fora, Juiz

de fora, 2017. Disponível em: https://repositorio.ufjf.

br/jspui/handle/ufjf/5803 Acesso em: 20 nov. 2019.

UNIVERSIDADE FEDERAL DE PELOTAS. Informações sobre

a Casa do Estudante Universitário. PRAE - Pró-Reitoria

de Assuntos Estudantis, 2019. Disponivel em: https://

wp.ufpel.edu.br/prae/2019/01/24/informacoes-sobre-a-

casa-do-estudante-universitario/. Acesso em: 01 out. 2019. 